This manuscript is a preprint. The manuscript's status is currently 'submitted' for editorial assessment and a peer-review process. It has yet to be accepted for publication. Subsequent versions of this manuscript may have slightly different content. If accepted, the final version of this manuscript will be available via the 'Peerreviewed Publication DOI' link. Please feel free to contact the corresponding author; we welcome feedback.

\title{
Acting on Sustainable Development Goal (SDG) synergies and trade-offs requires policy-focused systems tools
}

\author{
Enayat A. Moallemi ${ }^{1}{ }^{*}$, Seyed Hossein Hosseini' ${ }^{2}$, Sibel Eker ${ }^{3,4}$, Lei Gao ${ }^{5}$, Edoardo Bertone ${ }^{6,7,8}$, \\ Katrina Szetey ${ }^{1}$, Brett A. Bryan ${ }^{1}$
}

${ }^{1}$ Centre for Integrative Ecology, School of Life and Environmental Sciences, Deakin University, Melbourne, Australia.

${ }^{2}$ The Management Systems Engineering Institute (SAMAM), Tehran, Iran.

${ }^{3}$ Nijmegen School of Management, Radboud University, The Netherlands.

${ }^{4}$ International Institute for Applied Systems Analysis, Laxenburg, Austria.

${ }^{5}$ The Commonwealth Scientific and Industrial Research Organisation (CSIRO), Waite Campus, Australia.

${ }^{6}$ School of Engineering and Built Environment, Griffith University, Gold Coast, Australia.

${ }^{7}$ Cities Research Institute, Griffith University, Southport, Australia.

${ }^{8}$ Australian Rivers Institute, Griffith University, Nathan, Australia.

* Corresponding author: Enayat A. Moallemi (e.moallemi@deakin.edu.au)

\section{ABSTRACT}

Achieving the Sustainable Development Goals (SDGs) is contingent on managing complex interactions that create synergies and trade-offs between different goals. Given the importance of interactions, it is necessary to understand the system mechanisms underpinning them to provide insight into their non-linear behaviours such as side-effects, delay, and acceleration. Prominent methods of SDG analysis that focus on sector-specific modelling or data-driven statistical correlation are insufficient for presenting an integrated view of interactions among many goals. These methods are also often too technically complex or heavily data-driven to provide decision-makers with a simple practical tool and easily actionable and understandable results. To address this gap, we introduce a systems approach for analysing the SDGs that generalises a number of recurring interactions with unique structures and behaviours termed archetypes. We present eight interaction archetypes as thinking aids to conceptualise and analyse some of the important synergies and trade-offs, supported by several empirical studies related to the SDGs (e.g., poverty, food, well-being, water, energy, housing, climate, land-use). We also discuss how this approach can be operationalised in practice and what opportunities and challenges are ahead. Interaction archetype analysis advances sustainability science by giving researchers and policy-makers a diagnostic tool to identify fundamental mechanisms of barriers or policy resistance to SDG achievement, a comparative tool that can enhance knowledge transfer about the SDGs between different cases which share similar causal characteristics in a more coordinated way, and a prospective tool to design synergistic and transformational solutions for sustainable development.

\section{KEYWORDS}

Sustainability, SDGs, complexity, model, interaction, trade-off, system dynamics. 


\section{INTRODUCTION}

The Sustainable Development Goals (SDGs) represent a comprehensive agenda that contains both diverging and mutually supportive economic, social, and environmental goals (1). The SDGs are diverse and are underpinned by a network of highly interconnected socio-technical and socioecological systems, and their achievement depends on understanding and managing these crosssectoral interactions (2). This can include both promoting synergies (where multiple goals strengthen one another) and limiting trade-offs (where multiple goals hinder one another) (3, 4). For example, efforts to mitigate climate change (SDG 13) through negative emissions technology (e.g., afforestation or bioenergy crop plantation with carbon capture and storage) can create synergies with other goals and also enhance the health and well-being of communities (SDG 3) through reducing negative health impacts of extreme weather conditions (e.g., lowering heatwave frequency, improving air quality). Conversely, they can also have trade-offs such as negatively impacting terrestrial ecosystem health (SDG 15) and reducing food availability and increasing price (SDG 2) via competition for land and water (5). Understanding these causal interactions is important for creating coherent, high-leverage policies that can take into account interdependencies and offer integrated and complementary solutions for sustainable development (6).

In sustainability science, the study of interactions as synergies and trade-offs has a relatively long history prior to the SDGs, for example, in the context of the Millennium Development Goals $(7,8)$, climate change assessment (9-11), and the early works on balancing social, economic, and environmental development $(12,13)$. Interests in interactions have increased over recent years with the initiation of the SDGs. Given the unanimous agreement on the importance of interactions in the SDGs framework, studies have started to focus on SDG interactions as a field of scientific inquiry in its own right, developing new tools, analytical insights, and model-based projections (2, 4, 14-17). These studies have used various quantitative and qualitative methods, such as consensus-based expert elicitation $(2,16)$, literature-based content analysis $(15,17)$, indicator-based pairwise statistical correlation (3,4), statistical modelling of interactions (18), network analysis (19), and integrated assessment modelling $(14,20-22)$. Some of these studies have focused only on sector-specific interactions (e.g., energy (23), health (24), food (25)) while some other have had a more overarching approach and included many of the SDGs simultaneously $(3,4,22,26)$. Questions addressed so far have been mostly related to mapping the degree of association between various SDGs based on (historical or extrapolated) data $(3,4)$ or quantitatively projecting SDG trajectories under future scenarios $(21,22)$.

Despite the increasing number of analyses of SDG interactions, no research has so far provided a system-level understanding of underlying causal mechanisms and insights about their generated patterns of behaviour. Addressing this gap requires the adoption of systems science tools (27-30), which can move beyond the study of interactions as individual linear links, and frame them as recurring patterns of connected feedback loops, whose reinforcing and stabilising effects can cause nonlinearity in progress towards the SDGs (e.g., acceleration, disruption, step changes, and tipping points).

In this article, we introduce a systems approach to conceptualise SDG synergies and trade-offs as a set of generalised recurring interaction archetypes with unique underlying causal structures, fundamentally different dynamic behaviour, and therefore alternative policy and planning implications for sustainable development. These interaction archetypes, adopted from systems science (Methods), can be seen as the building blocks or unit of analysis in SDG synergy and trade-off studies, which can occur at any scale or in any context. They can also be combined to explain a more complex 
representation of multiple interacting synergies and trade-offs (27). We illustrate the utility of the archetypal patterns of interaction with some simple multidisciplinary examples of the most frequent SDG synergies and trade-offs that have been observed and reported at a global scale $(3,4)$. The suggested analysis of the SDGs with interaction archetypes can help researchers and practitioners better understand the similarities and differences of sustainability interactions in relation to their feedback-rich structures and dynamic behaviour, beyond the limits of any specific sectoral contexts. Adopting a systems lens in analysing SDG interactions can also inspire a new stream of research for better understanding the underlying causal processes for sustainable development and anticipating and managing them in advance to accelerate progress towards the SDGs (31).

\section{INTERACTION ARCHETYPES}

We present below the proposed set of SDG interaction archetypes with examples from the literature and by explaining how they are created, what their expected dynamic behaviour is, and what their policy and planning implications are for sustainability (Table 1). The archetypes were ordered based on their similarity of what drives the interactions.

Table 1. A summary of interaction archetypes in the SDG context. Icons adapted from the Noun Project under a Creative Commons License CC BY 3.0: target by Adrien Coquet, band-aid by Alice Design, arrow by Saeful Muslim, iceberg by Colourcreatyp, fists by Vectors Point, coins by Tanmay Goswami, barrier by Optimus Prime, and fishes by Badsha Mia.

\begin{tabular}{|c|c|c|c|c|}
\hline Driver & $\begin{array}{l}\text { Interaction } \\
\text { archetype }\end{array}$ & Description & Potential behaviour & Example \\
\hline 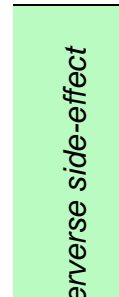 & Fixes That Fail & $\begin{array}{l}\text { SDG interventions end up with opposite } \\
\text { effects due to delayed trade-offs with } \\
\text { other goals } \\
\text { Band-aid solutions with short-term } \\
\text { moderate impacts diminish the need for } \\
\text { transformative SDG interventions }\end{array}$ & $\begin{array}{l}\text { Slowing progress due to declining } \\
\text { presence of long-term interventions }\end{array}$ & (33) \\
\hline 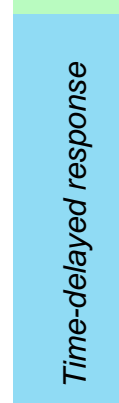 & $\begin{array}{l}\text { Eroding } \\
\text { Dombitions } \\
\text { Problems }\end{array}$ & $\begin{array}{l}\text { Long-term interventions with time- } \\
\text { delayed response create uncertainty } \\
\text { about SDG achievement and justify lower } \\
\text { ambition } \\
\text { The ignorance of trade-offs which are } \\
\text { seemingly insignificant due to their time- } \\
\text { delayed response but will eventually } \\
\text { overshadow all synergistic interactions } \\
\text { and can halt or reverse progress }\end{array}$ & $\begin{array}{l}\text { Increasing progress, but towards } \\
\text { low-ambition goals that can be } \\
\text { easily achieved } \\
\text { Initial progress due to synergistic } \\
\text { interactions, followed by rapid } \\
\text { decline from the prevailing effects of } \\
\text { downplayed trade-offs }\end{array}$ & (35) \\
\hline 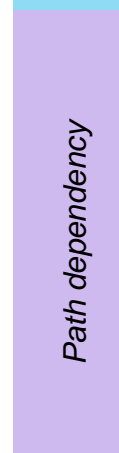 & $\begin{array}{l}\text { Escalating } \\
\text { Tensions } \\
\text { Success to the } \\
\text { Successful }\end{array}$ & $\begin{array}{l}\text { Resources are diverted towards goals } \\
\text { with historically better performance and } \\
\text { away from other more challenging and } \\
\text { interacting goals which reduces progress }\end{array}$ & $\begin{array}{l}\text { Increasing trade-offs between } \\
\text { conflicting goals with accumulating } \\
\text { progress towards one goal at the } \\
\text { cost of declining progress towards } \\
\text { others }\end{array}$ & $(36)$ \\
\hline
\end{tabular}




\begin{tabular}{|l|l|l|l|l|} 
& $\begin{array}{l}\text { Limits to } \\
\text { Progress }\end{array}$ & $\begin{array}{l}\text { Interventions reliant on exhaustible } \\
\text { resources can produce diminishing } \\
\text { returns over time as resources reach } \\
\text { their limit }\end{array}$ & $\begin{array}{l}\text { Progress stabilises or declines } \\
\text { despite increasing efforts }\end{array}$ & $(34)$ \\
& $\begin{array}{c}\text { Commons } \\
\text { Pragedy of the }\end{array}$ & $\begin{array}{l}\text { Pursuing goals in isolation by actors } \\
\text { interested in only a specific sector can } \\
\text { exhaust common resources and lead to } \\
\text { an overall unsustainable outcome for all }\end{array}$ & $\begin{array}{l}\text { Increasing progress in one goal, at } \\
\text { the cost of declining progress in } \\
\text { other goals and an overall } \\
\text { unbalanced achievement }\end{array}$ & (38) \\
\hline
\end{tabular}

\section{Fixes That Fail}

Fixes That Fail represents SDG interactions that are driven by the interplay and conflict between (short-term) planned and (long-term) unexpected outcomes of interventions, resulting in perverse side-effects in progress towards sustainability. It implies that interventions which can positively impact a goal in the short-term can sometimes result in unintended consequences and trade-offs with other goals, stopping or even reversing the progress made.

The causal configuration behind this type of interaction involves balancing and reinforcing feedback loops (Figure 1a), which can be explained in the context of food and agriculture and through tradeoffs between SDGs 2 Food Security and 13 Climate Action (Table S1). Within the food and agriculture system, SDG 2 focuses on both achieving zero hunger and promoting sustainable agriculture. While both seem to be supportive of each other, they can also have trade-offs. A quick and seemingly effective fix to address food insecurity can be through boosting food production via unsustainable practices such as agricultural land expansion or excessive fertiliser use. The expansion of agricultural lands and increase in food production might seem the quickest solution for addressing food insecurity, but it can also cause side-effects, such as deforestation from agricultural expansion and increasing greenhouse gas emissions from agricultural production, both with reinforcing impacts on climate change (SDG 13). These side-effects can subsequently reduce agricultural yield and damage food security in the long-term.

A practical example comes from Nigeria where, during the last few decades of the $20^{\text {th }}$ century, increasing population and in turn the prevalence of unsustainable farming practices such as shorter natural fallow periods to meet food demand, contributed to the proportion of degraded soil increasing to $69 \%$ (39). This caused deforestation, eventually leading to further reduced soil fertility, and in turn exacerbating food insecurity (39). A more recent study (40) also highlighted how $78 \%$ of deforestation in Latin America is driven by agricultural needs, leading to high emissions from agriculture-driven deforestation. This in turn can lead to an exacerbation of climate change and its effects, which already includes higher risks of drought (41) and in turn, lower agricultural productivity. Other applications of Fixes That Fail also include case studies in relation to different sustainability areas (e.g., bioenergy, food and agriculture, land sectors), for example to understand in the side-effects in the governance and policy-making process in regional Italy (32) and the unintended consequences of land-use change on local communities in the north central region in USA (42).

A potential dynamic behaviour is short episodes of progress improvement due to short-term actions but with a steadily worsening long-term trend due to delayed unintended consequences of those temporary actions (Figure 1b). As a result, the original sustainability problems can still persist, and progress can be slowed (or reversed) despite increasing efforts. 
One of the policy implications of this interaction archetype is the importance of understanding and preparing for policy side-effects of short-term fixes. In practice, this means whenever designing temporary, short-term fixes is necessary to address immediate problems, corrective actions should also be taken to mitigate the unexpected negative consequences. At the same time, preparing and planning for long-term high-leverage interventions can also become important to address the main cause of the problems and ensure long-term progress.

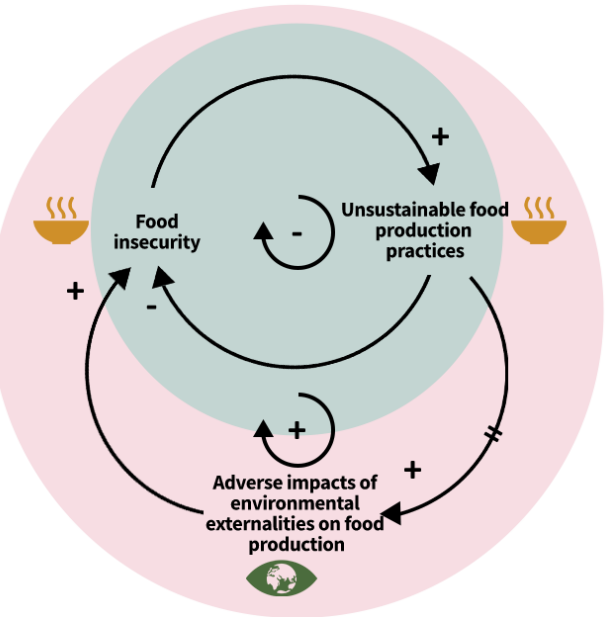

(a)

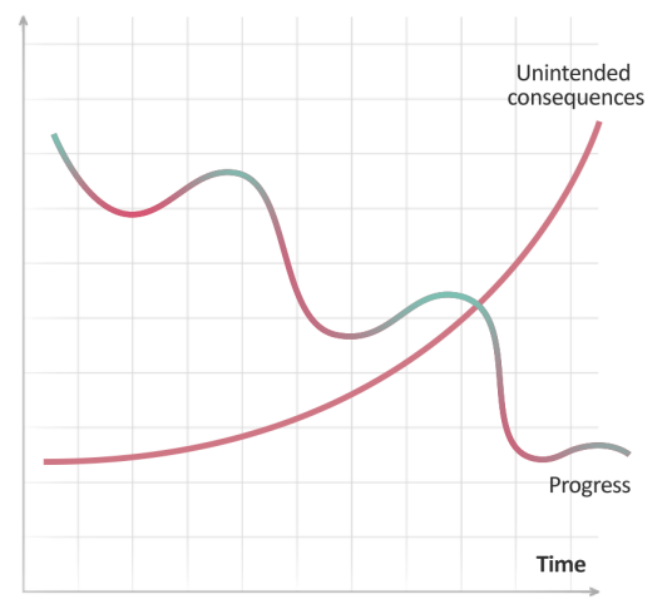

(b)

Figure 1. (a) The causal configuration and (b) a potential dynamic behaviour in Fixes That Fail. The major feedback interactions in (a) and their corresponding impacts in (b) are colour coded.

\section{Band-Aid Solutions}

Band-Aid Solutions (aka Shifting the Burden) represents SDG interactions driven by short-term, relatively easy interventions and their undesired effects (perverse side-effect) in eroding the need for long-term, transformative interventions. It explains how temporary solutions which can only deliver moderate progress can misleadingly diminish the need for and undermine the urgency of fundamental interventions which target the root cause and promote transformation. Band-Aid Solutions is similar to Fixes That Fail in a sense that they both highlight the peril of actions with side-effects. However, while Fixes That Fail highlight a more direct definition of side-effects in terms of unintended consequences of short-term actions, Band-Aid Solutions shows a more complex side-effect where the negative effect on progress comes through diminishing the need for bolder interventions.

The typical causal configuration behind this type of interaction involves the interplay between at least two balancing and one reinforcing feedback loops (Figure 2a). We explain them here in the context of interactions between SDGs 1 No Poverty and 7 Energy Security and SDGs 1 and 13 Climate Action (Table S1). One commonly used solution to improve the living conditions of people in developing countries is to subsidise (or not limit the excessive use of) exhaustible natural energy resources (e.g., petrol/LPG for mobility and traditional biofuel gas stoves) (SDG 7). In the short-term, this solution clearly addresses poverty by reducing (or at least not increasing) the cost of living (SDG 1). However, in the long-term, increasing welfare can lead to more consumption, which subsequently makes the emerging needs outweigh energy supply and available infrastructure, stabilising or even reducing access to basic needs and thereby perpetuating poverty. More importantly, achieving short-term success with temporary solutions such as subsidised fossil energy may reduce the urgency and perceived need for taking transformational actions to address climate change (e.g., improving climate resilient agriculture, better response to droughts or flooding, using solar energy for cooking, using natural light reflectors for buildings), as a fundamental reason that can underpin poverty in the longterm. Climate change is inextricably linked to poverty and can disproportionally affect poor people in 
low-income communities (43). A reduced urgency for climate actions can exacerbate poverty in the future (43). Other applications of Band-Aid Solutions include, for example the identification of similar problems in pasture management in the Caucasus (Azerbaijan and Georgia) in relation to the interactions between agriculture (SDG 2), life on land (SDG 15), and governance (SDG 16) (33).

One potential dynamic behaviour of such interactions is a temporary period of incremental progress due to increasing short-term efforts (Figure $2 b$ ). However, the overall long-term progress has a declining trend, and transformational change is unlikely to be achieved due to a lack of fundamental change. In our poverty example, it means that persisting with subsidies and utilising more fossil fuels would lead to a short-term decline in the cost of living, but it would be likely to add to poverty due to further impacts of climate change (e.g., wildfires, flooding), further exacerbated by delays in taking necessary action. Referring again to Nigeria (39), population growth over the second half of the $20^{\text {th }}$ century led to a large increase in demand for charcoal, which in turn exacerbated deforestation. In combination with other factors, this led to several years of large GDP growth (especially in the '70s), while deforestation exacerbated climate change effects, causing deeper and more frequent droughts, and in turn negatively affecting Nigeria's economy (44). Other examples are provided by countries whose economy and energy sectors heavily rely on coal mining, such as Poland (45), which had longstanding subsidies that declined only slowly over time, in order to limit the short-term economic impact of a large-scale, abrupt transition to cleaner energy sources.

One of the policy implications of this interaction archetype is to better understand and differentiate between the effects of SDG actions, i.e., temporary band-aid versus fundamental long-term interventions. Similar to the implications from the previous archetype, it is important that policy-makers remain aware of temporary intervention side-effects and plan in advance for fundamental actions to lay the ground for long-term transformational change and avoid future delays. In our poverty-energy example, several studies, both global and country-specific, have demonstrated that the medium- to long-term benefits of policies aiming at de-incentivising fossil fuel production outweigh the minor shortterm costs. For instance, in Turkey (46), the potential removal of subsidies could reduce emissions by $5 \%$ with only minor effects on the economy; while in Australia (47), with related policies such as the Emission Reduction Fund, small $(<0.6 \%)$ GDP reductions could be expected, leading however to significant emission abatements and contributing to longer-term climate change mitigation (48).

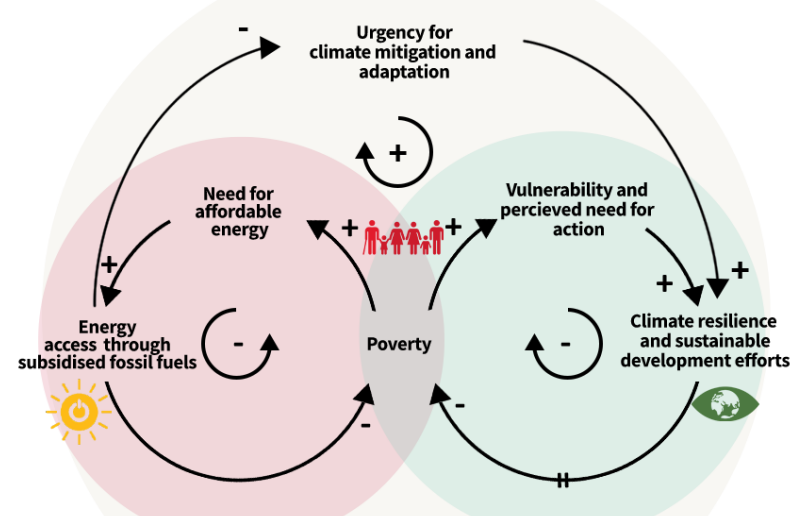

(a)

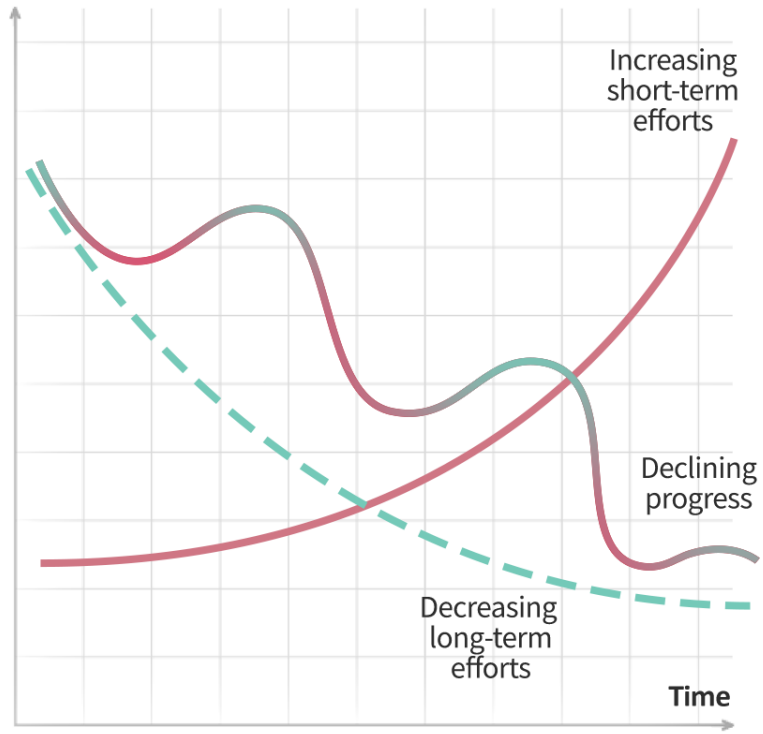

(b)

Figure 2. (a) The causal configuration and (b) a potential dynamic behaviour in Band-Aid Solutions. The major feedback interactions in (a) and their corresponding impacts in (b) are colour coded. 


\section{Eroding Ambitions}

Eroding Ambitions (aka Drifting Goals) represents SDG interactions resulting from the time-delayed response of interventions and losing hope in making progress. Delays in achieving expected progress and uncertainty about the effectiveness of long-term actions can undermine the need for their presence and for having ambitious sustainability goals. This can lead to lower goals that are more achievable in the short-term but are not necessarily adequate for sustainability in the long-term.

The causal configuration that underpins this interaction involves at least two balancing feedback loops (Figure 3a). They can be explained with an example in the context of interactions between SDGs 13 Climate Action and 7 Energy Security and SDGs 13 and 9 Industry, Innovation, and Infrastructure (Table S1). Commitments to achieving zero carbon emissions (SDG 13) are largely reliant on the transformation of the energy sector towards cleaner (renewable) energy production (SDG7). However, increasing the share of renewable energy for emissions reduction is not always the first priority in developing countries who often have a strong economy-focused development agenda. Shifting to renewable energy for these countries can result in the replacement of depreciated capacities and improvement of low-efficiency energy infrastructure rather than investing in the expansion of their total energy production capacities (which is more important for economic development). In the short-term, this can make energy supply fall short of growing demand and limit the expansion of industry (SDG 9). Given the limited infrastructure and potential trade-offs with economic growth, a major policy concern can arise around the effects of ambitious climate goals and the ability to achieve net zero emissions in a timely manner. The resulting disruptive impacts on other sectors can challenge the legitimacy of ambitious goals and stall the transition to renewable energy. Such a lack of legitimacy can put pressure to lessen the ambition of emissions reduction targets. Australia is an example of a country with low-ambition emissions reduction targets which have arisen from short-term political goals, the heavy reliance of the country's economy on coal mining, and difficulties with accelerating the transition to renewables (49). This is in stark contrast with countries such as Germany and the United States where domestic coal mining has already ended or has drastically diminished. Other applications of Eroding Ambitions exist in other sectors (e.g., agriculture (34), land-use change (42)). For example, in the development of organic farming in the European Union which has shown that continuous improvement of ambitious regulatory standards is necessary to ensure long-term performance (34).

A potential dynamic behaviour is gradual progress (i.e., for emissions reduction), but slow progress towards a low-ambition, inadequate sustainability goal (Figure 3b). In our previous example, this behaviour results from an increasing tension and trade-offs between pursuing the long-term climate goal with transition to renewables (SDGs 7 and 13), and the short-term goal of supporting industrial sectors and avoiding disruption at the expense of climate change (SDGs 9 and 13).

One of the important policy implications of this interaction is the importance of perseverance and patience in making tangible progress and achieving ambitious goals. SDG interactions are non-linear. This means that initial efforts towards long-term goals may start slowly, but they can accelerate and pay off later if they continue. Therefore, the careful management of short-term expectations and a better understanding of non-linearity between actions and their impacts among stakeholders is necessary to avoid a backlash and disappointment. Educational and informational tools (e.g., social media campaigns, fund raising) which can increase public awareness about past achievement and highlight tangible future benefits (e.g., job creation, poverty alleviation, less pollution) can be helpful for maintaining the legitimacy of ambitious goals and actions. The use of mixed interventions (e.g., philanthropic/NGO and government funding) which support the provision of resources for both 
immediate (e.g., socio-economic development) projects and those with longer term sustainability benefits can be another way to increase legitimacy and reduce the pressure to lower ambition.

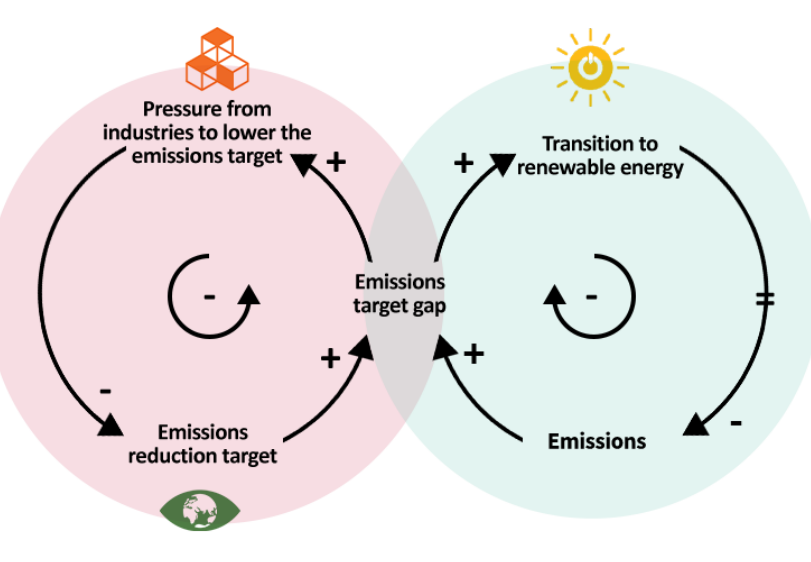

(a)

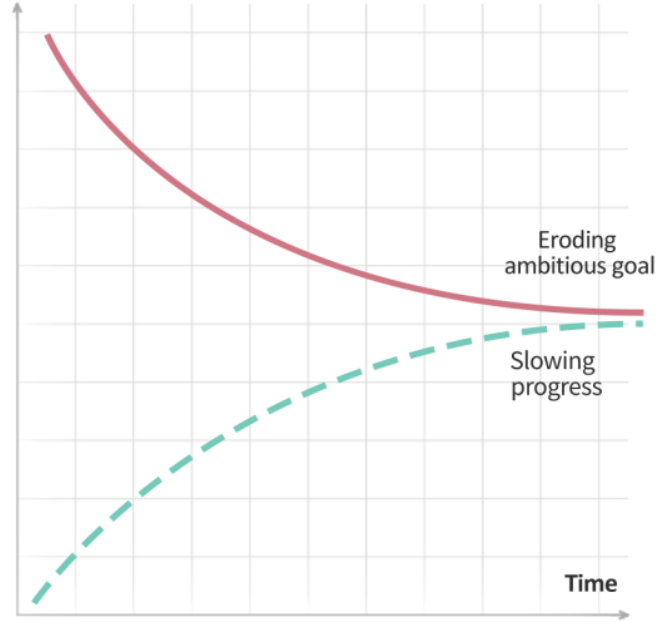

(b)

Figure 3. (a) The causal configuration and (b) a potential dynamic behaviour in Eroding Ambitions. The major feedback interactions in (a) and their corresponding impacts in (b) are colour coded.

\section{Downplayed Problems}

Downplayed Problems (aka Growth and Underinvestment) represents a more complex version of Eroding Ambitions with a time-delayed response effect. Interventions, which stimulate and reinforce progress towards one goal, may not remain effective in the long-term as progress approaches a limit resulting from a (delayed) trade-off with other conflicting goals. Efforts to eliminate or alleviate the trade-off and push the progress limit can take years to materialise. This can justify downplaying the importance of addressing trade-offs with conflicting goals, which will eventually lead to worse effects in the long-term.

The causal configuration behind this type of interaction involves the interlinkage of at least two balancing and one reinforcing feedback loops (Figure 4a). We explain them in the context of synergies between SDGs 11 Sustainable Cities and Communities and 8 Economic Growth and trade-offs between SDGs 11 and 3 Health and Well-Being. With economic growth and improving incomes (SDG 8), people are often attracted to cities where jobs and opportunities exist and where living standards are higher. This leads to demand for expanding cities and infrastructure (SDG 11), in turn providing even greater capacity to attract more people and promoting further economic growth and development. However, increasing population can stretch cities beyond their sustainability standards, with trade-offs with health and wellbeing from communicable and non-communicable diseases, hazardous chemicals, and pollution (SDG 3). This has been experienced in cities around the world, such as in Bangladesh (50) and in multiple African cities (51), making growing urban areas less liveable in the future. Interventions to address this trade-off can include making cities more sustainable by investing and enhancing their liveability (e.g., investing in mental health and well-being, public green space, waste management, and air pollution reduction). However, the impacts of these interventions are often observed with lags and delays and require time to materialise, which can reduce confidence in their ability to deliver outcomes. Alternatively, a (misleadingly appealing) approach can be to downplay the trade-off problem by redefining city liveability standards to suit the current unsustainable conditions and further stretching the cities beyond their sustainable limits in order to boost socio-economic development. The actual effect of this downplayed trade-off will eventually dominate any positive synergies in the system and can lead to a slowing of economic growth in the long-term. There are other applications of this type of interaction in the literature, for 
example in the context of water synergies and trade-offs (SDG 6) with other sectors, their downplayed problems, and the leverage points for interventions (35).

A potential dynamic behaviour in the short-term is initial rapid progress due to the synergistic reinforcing feedback loop (e.g., between SDGs 8 and 11). However, this will be followed by a longer term decline in progress due to a delayed trade-off with other goals (e.g., SDG 3) and eroding ambition in other conflicting goals (Figure $4 b$ ).

One of the policy implications of this type of interaction is the importance of anticipating and planning for delayed appearance of limiting progress and the trade-offs that lead to it (e.g., city liveability) in advance. Anticipating and planning for the delayed trade-offs require a monitoring of the external environment to detect signals that can indicate a slowing in progress towards sustainability goals, thereby enabling policymakers to respond in advance with corrective actions. Another implication stresses the importance of improving public awareness, for example about the dependency of socioeconomic development on environmental sustainability and the necessity of maintaining and investing in high standards for 'sustainable' development.

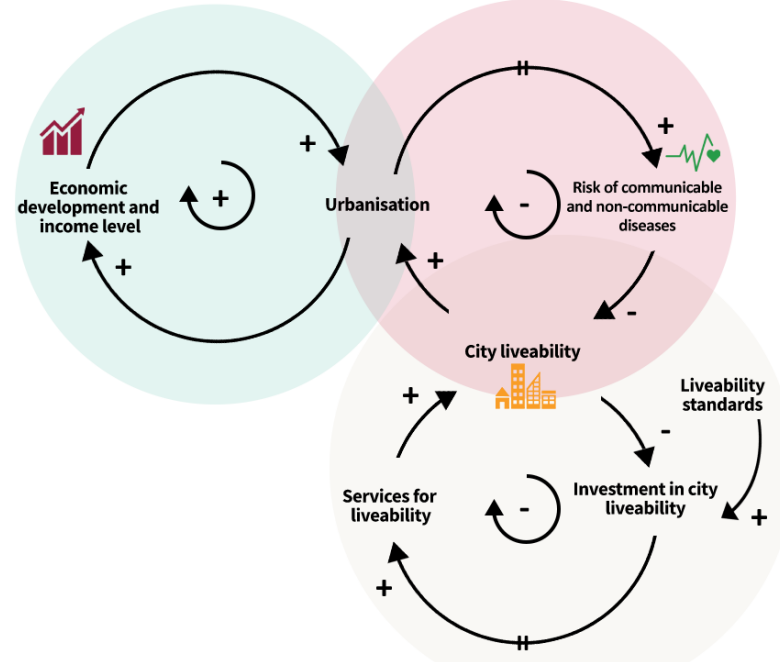

(a)

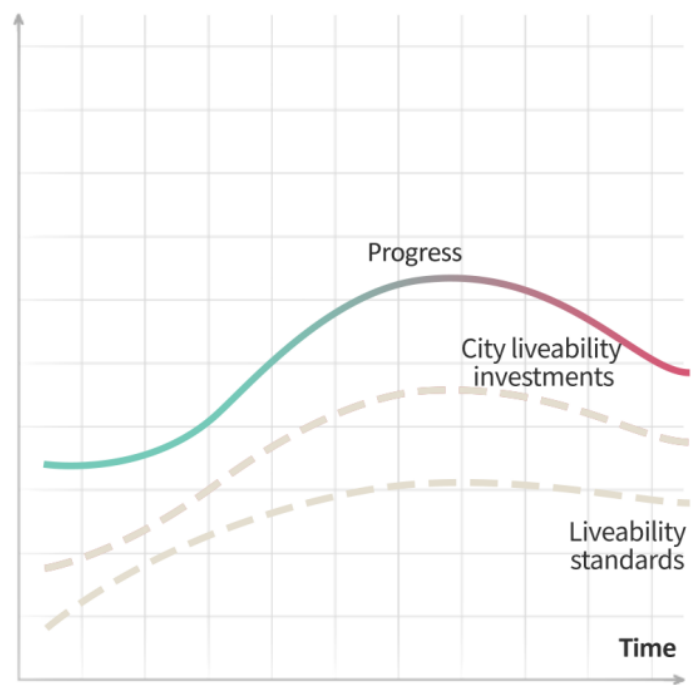

(b)

Figure 4. (a) The causal configuration and (b) a potential dynamic behaviour in Downplayed Problems. The major feedback interactions in (a) and their corresponding impacts in (b) are colour coded.

\section{Escalating Tensions}

Escalating Tensions (aka Escalation) represents SDG interactions driven by path dependency to short-term, temporary interventions with unsustainable outcomes. It implies that short-term interventions which can deliver slow progress can result in unintended consequences which require further temporary fixes to maintain even this slow progress. The increasing number of path dependent temporary interventions can drain resources for taking fundamental actions and can result in progress stagnation (or even deterioration) in the long-term.

The causal configuration underlying this type of interaction involves at least two interlinked balancing feedback loops (Figure 5a). We explain them in the context of interactions between SDGs 11 Sustainable Cities and Communities and 9 Industry, Innovation, and Infrastructure. Expanding cities through constructing houses in sprawling suburbia is often a solution to address increasing demand and ensure housing affordability (SDG 11). Increased suburban housing supply, however, increases pressure on current infrastructure (e.g., road, water, energy, healthcare) (SDG 9). This mounting pressure, along with the advocacy power of local communities in suburban areas, can be used to 
justify new infrastructure projects to meet the increasing demand. This is true for cities like Melbourne, Australia where adding transportation costs to low-affordability housing makes many suburbs extremely expensive to live in (52). New infrastructure projects increase the attractiveness of investing in housing, thereby exacerbating demand. In the long-term, this can further reduce housing affordability and promote the expansion of cities (and subsequently the need for more infrastructure). There are also other applications of Escalating Tensions in the literature, for example in the context of pig farming in Ghana for analysing how tension and business rivalry behaviour for access to resources within the piggery industry can lead to an overall productivity decline (36).

A potential dynamic behaviour would be an initial synergistic effect between the interacting goals (e.g., improving infrastructure in suburbia helps housing affordability). However, this synergy diminishes, leading to declining progress towards both goals over time (e.g., housing affordability deteriorates and infrastructure remains insufficient and ineffective). This diminishing synergistic interaction can appear as a generally declining behaviour where initial progress, occurring when interventions are imposed, is followed by deterioration due to the effects of other temporary interventions (Figure $5 b$ ).

An implication for sustainability planning is that a synergistic interaction, if managed inappropriately and through path dependent and temporary interventions, can result in negative outcomes for the SDGs in the long-term and derail sustainable development. Hence, it is important to consider path dependency in the long-term to maintain and benefit from synergistic SDG interactions.

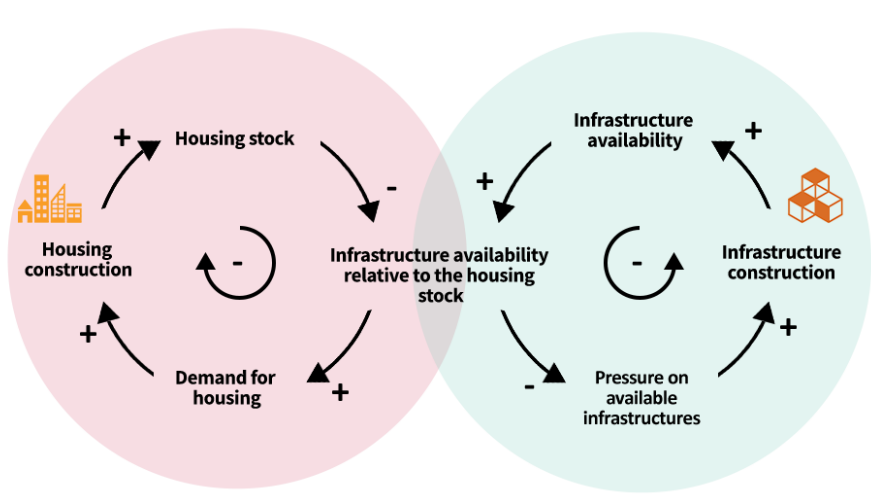

(a)

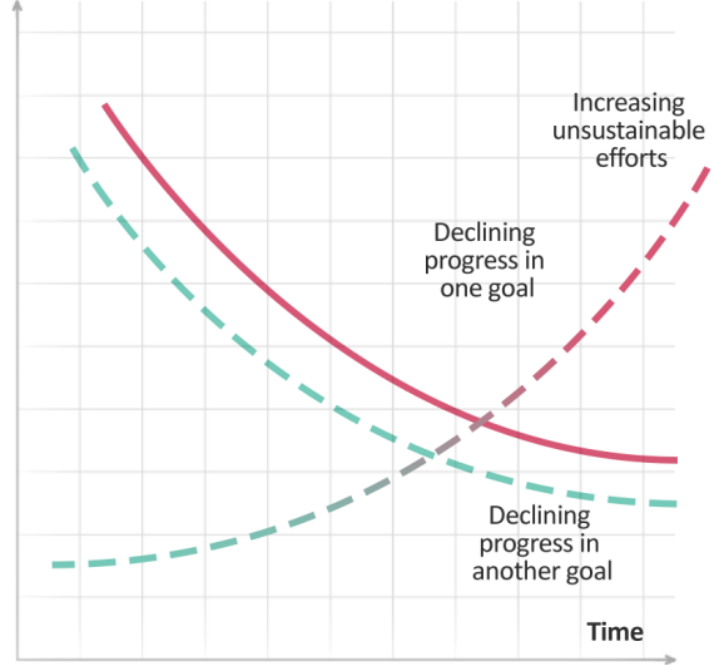

(b)

Figure 5. (a) The causal configuration and (b) a potential dynamic behaviour in Escalating Tensions. The major feedback interactions in (a) and their corresponding impacts in (b) are colour coded.

\section{Success to the Successful}

Success to the Successful represents SDG interactions resulting from a similar path dependency effect. Efforts to make progress exhibit path-dependency with goals which have historically better performance, less uncertain outcomes, higher public legitimacy, and/or less delayed response. Goals with path dependency can attract more resources (e.g., financial, policy support, human capital) with the expectation that their success will continue in the future. However, they take away resources from other goals and this can limit their progress.

The causal configuration underpinning this type of interaction involves at least two reinforcing feedback loops (Figure 6a). We explain these in the context of competition for resources between economic development and environmental conservation (SDGs 8 and 15). Job creation, economic productivity, and economic growth (SDG 8) are some of the key priorities in development programs. 
An economy-focused agenda is often able to deliver outcomes quickly such as reduced poverty, more jobs, and better infrastructure, and typically have more (short-term) successes. Nature conservation and ecosystem protection (SDG 15) is a key priority which can help improve environmental health as well as maintain and even accelerate economic growth (e.g., via halting biodiversity loss and increasing revenue from tourism). However, efforts to integrate ecosystem and environmental protection values into development programs are less common and lower priority due to delays between actions and their tangible impacts (e.g., it may take decades to reverse biodiversity loss and it may be difficult to verify). Hence, there are fewer success stories to convince the public and policymakers. They are also less desirable to policy-makers who often favour less change with actions which are part of an incumbent regime and who want to achieve outcomes within their short accountability period. This can redirect the share of resources and give more attention to economyfocused agendas with a proven historical performance and shorter-term outcomes. There are other applications of Success to the Successful in a sustainability context (e.g., in agriculture (53), land management (42)), for example in relation to the water-food-energy nexus in West Java in Indonesia for analysing how resources (i.e., reservoir water) should be divided properly between different sectors to avoid the Success to Successful issue and achieve sustainable development (37).

One potential dynamic behaviour of this interaction is an increasing trade-off that a path dependent goal makes with other sustainable development goals (Figure 6b). For any goal, the allocation of sufficient resources is necessary to make progress. Therefore, the allocation of further resources to path dependent goals brings more success and creates more justification (e.g., growth of interest groups, lobby actions) for yet further allocation of resources in the future. Conversely, progress towards other goals from which resources are diverted from continues to deteriorate and the gap between the goals widens over time.

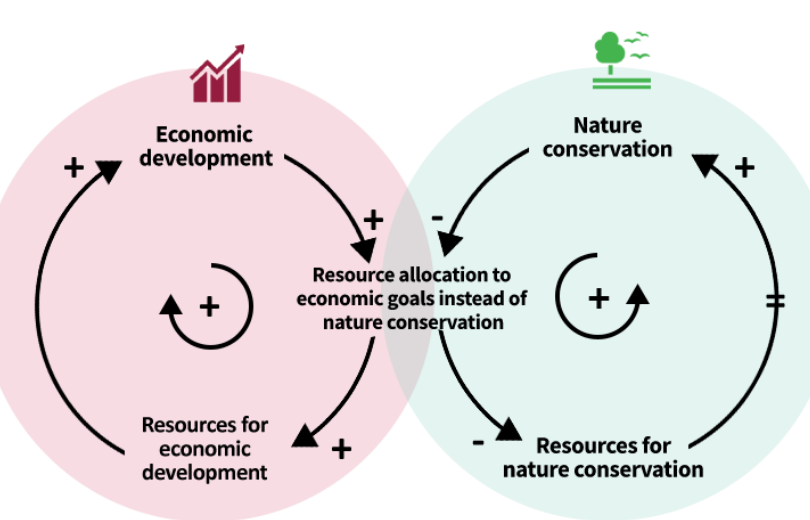

(a)

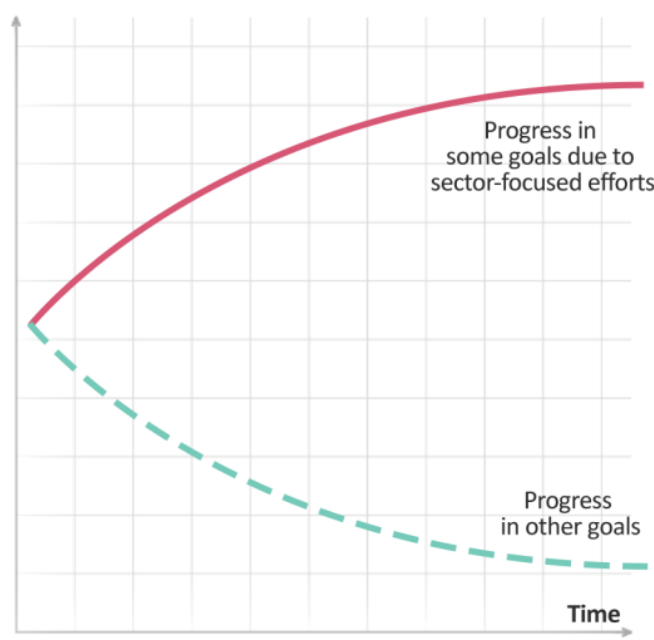

(b)

Figure 6. (a) The causal configuration and (b) a potential dynamic behaviour in Success to the Successful. The major feedback interactions in (a) and their corresponding impacts in (b) are colour coded.

A lesson learned from this type of interaction for sustainability planning is to maintain focus on the original SDG principle of striving for balanced progress across all goals. This, first of all, needs a better understanding of the origins and sources of competition between interacting goals with shared resources and being aware of those goals that could cause path dependency and deplete resources. As an example, studies have been conducted in the Democratic Republic of Congo to compare economic benefits from improved road connectivity and resulting loss in ecological value due to related deforestation (54). Second, it also needs measures that can support goals with less historically proven performance against path dependent goals. Examples include public awareness campaigns 
to adjust expectations about uncertainty and delay in progress towards other goals, new finance mechanisms where funds could be made available for experimenting with new goals, and advocacy coalition activities that can work as a catalyst and raise less progressed aspects of sustainable development as new priorities.

\section{Limits to Progress}

Limits to Progress (aka Limits to Growth) represents SDG interactions driven by a limiting condition effect where unsustainable interventions with huge short-term benefits can deplete exhaustible (e.g., natural, financial, human capital) resources and become counter-effective in the long-term. It captures how efforts to make an initial accelerating progress may not continue forever if they are strictly reliant on exhaustible resources. Unsustainable interventions can produce diminishing returns over time and the progress can be slowed, stabilised, or even reversed as resources reach their limit.

The causal configuration behind this type of interaction involves the interplay between balancing and reinforcing feedback loops (Figure 7a). In the context of the energy sector, this can be explained by interactions between SDGs 7 Energy Security and 9 Industry, Innovation, and Infrastructure and SDGs 7 and 12 Responsible Consumption and Production. Innovation and infrastructure projects (SDG 9) related to fossil fuel-based energy carriers (e.g., new technologies to improve fossil fuel extraction) can initially boost energy production and improve energy security (SDG 7). Incomes from the fossil fuel energy industry also further reinforce investments in fossil fuel technology and innovation. With this increase in energy production in the short-term, there can be a subsequent rise in per-capita energy consumption, and energy demand can increase exponentially. However, energy production based on fossil fuel technologies is restricted by the availability of natural resources and can cause significant trade-offs with sustainable production and consumption (SDG 12). The combination of fossil fuel reliance and resource depletion can mean that energy supply does not increase sufficiently in response to growing demand and energy insecurity may be even more acute in the long-term. A stark example is provided by India's heavy reliance on limited fossil fuel resources to meet their energy needs where recent shortages were predicted a decade ago as was the need to exploit alternative renewable energy sources $(55,56)$. Limits to Progress has been used frequently in other sustainability applications such as agriculture (34), food (38), energy (32), for example, showing that increasing agricultural subsidies does not always generate growth and can be limited by other factors such as market dynamics or intrinsic environmental limits (34).

A dynamic behaviour resulting from this interaction is an initial synergy (e.g., between SDGs 7 and 9), which diminishes over time due to trade-offs with other goals (e.g., SDG 12). With this decreasing synergy, rapid but short-term progress is expected initially (e.g., improving energy production due to technology innovation). However, this does not last long as progress slows, stagnates, or even declines in the long-term due to resource depletion despite increasing efforts and further investment (Figure 7b).

The most important sustainability implication is to anticipate in advance and take early actions to address the effects of limiting conditions in the design of SDG actions to avoid stagnation in the longterm. In our energy example, this means adopting measures that can help shift innovation and infrastructure development from fossil fuels to renewable technologies (e.g., imposing a green tax on fossil fuel projects to be invested in renewable energy capacity expansion) such as advocated for India $(55,56)$, to decouple energy production (SDG 7) from finite natural resources (SDG 12). Such sustainability actions may not deliver outcomes in the short term due to (decision-making and 
administrative) delays in adjusting to the new system and lags between policy and impact on the ground. However, they are capable of producing better long-term outcomes.

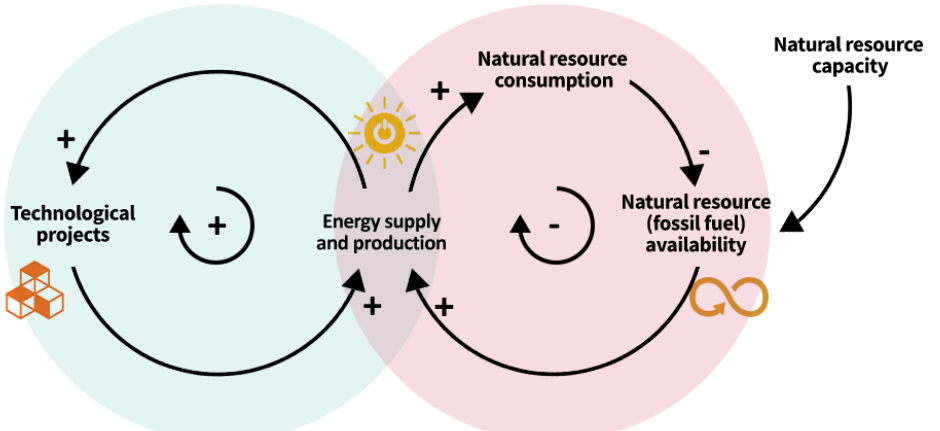

(a)

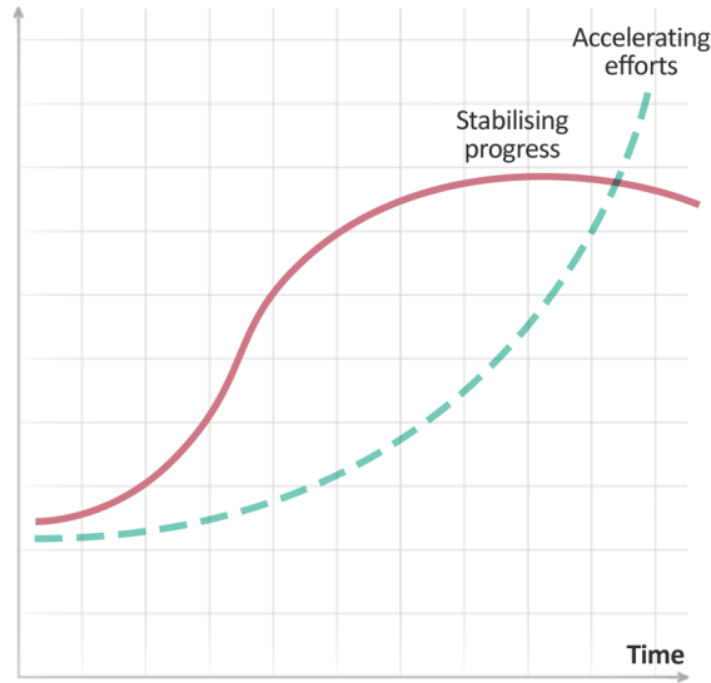

(b)

Figure 7. (a) The causal configuration and (b) a potential dynamic behaviour in Limits to Progress. The major feedback interactions in (a) and their corresponding impacts in (b) are colour coded.

\section{Tragedy of the Commons}

Tragedy of the Commons represents SDG interactions resulting from a more complex limiting condition effect, where working towards competing goals while sharing limited resources (e.g., water, land) in isolation could lead to the exhaustion of resources and an overall unsustainable outcome.

The causal configuration that underpins this type of interaction involves multiple reinforcing and balancing feedback loops (Figure 8a). The reinforcing loops drive competition between goals while balancing loops stabilise this progress due to the effect of a shared limited resource. We explain them in the context of trade-offs between the use of water (SDG 6) for energy (SDG 7) and food production (SDG 2). Energy production can have a substantial water footprint. Water is used in energy production for thermal cooling in power plants and in bioenergy and hydropower generation. Increased water allocation expands generation capacity and increases energy production, creating a path dependency with further water demand for energy. Water is also heavily used in agriculture for food production where increased water allocation leads to the expansion of agricultural activities and more food production. This eventually creates a reinforcing feedback loop further increasing water demand for expanded agricultural lands. The increasing competition between different sectors for water as a limited resource can increase water use (and potentially water pollution) and drive up the cost of water, diminishing the gains in energy and food production from available water. Notable examples include demand increases for water, energy, and food in the context of growing populations and poor intersectoral policy coordination in South Asian countries such as India, Pakistan, and Bangladesh (57), and similar problems potentially occurring in other countries such as Chile (58). Tragedy of the Commons has been also used in other sustainability applications, for example for analysing resourceconstraint issues in agriculture (59), water (60), and food (38) sectors.

A dynamic behaviour resulting from this interaction is a gradual decline in the common pool resource (water in our example). If left uncontrolled, this can continue until the commons are completely exhausted (or its cost skyrockets) and the achievement of the sustainability goals which rely on the resource can become impossible, with progress halted or reversed (Figure 8b). 
A policy implication of this type of interaction is the importance of understanding connections between sectors from a whole-of-system level and managing coordinated actions that can make appropriate trade-offs and make the best use of common pool resources. It also signifies the connection between uncoordinated actions towards individual goals occurring in isolation and the diminishing collective outcomes for sustainable development due to overloaded or depleted resources. The competition between goals and the limited resources can be managed through renewing, sharing, and reusing the commons before depletion (e.g., circular economy). The negative effects of competition and limiting conditions can be also reduced by decoupling the progress across interacting goals from the limited resources (e.g., farming less water intensive feed and food crops, shifting to less water intensive renewable energies like wind and solar).

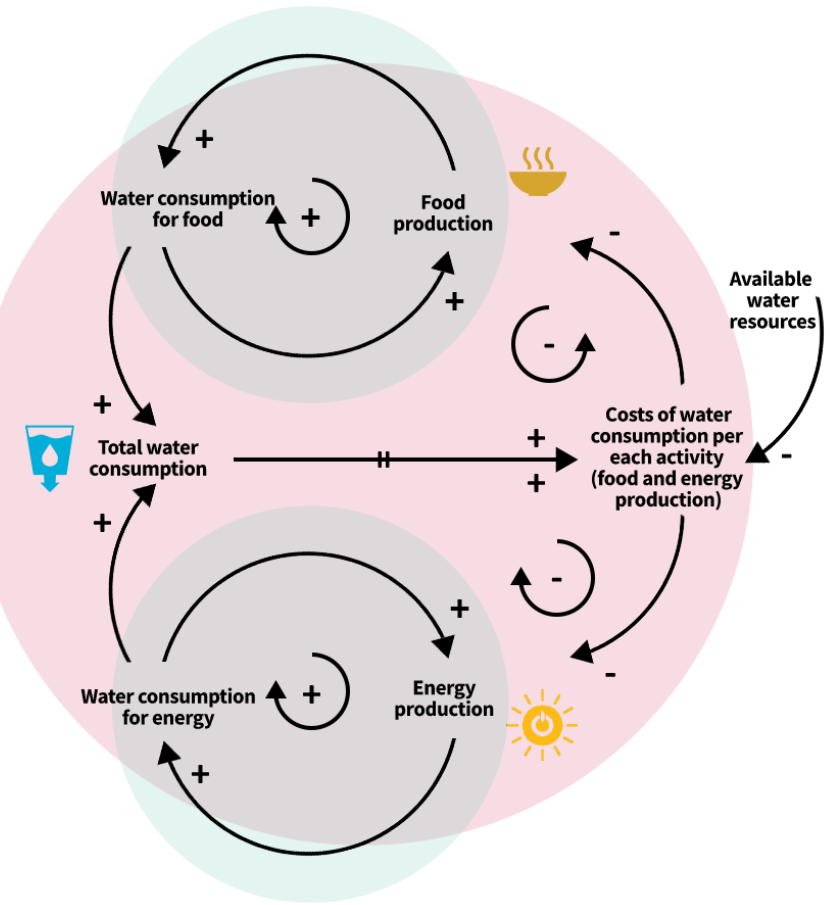

(a)

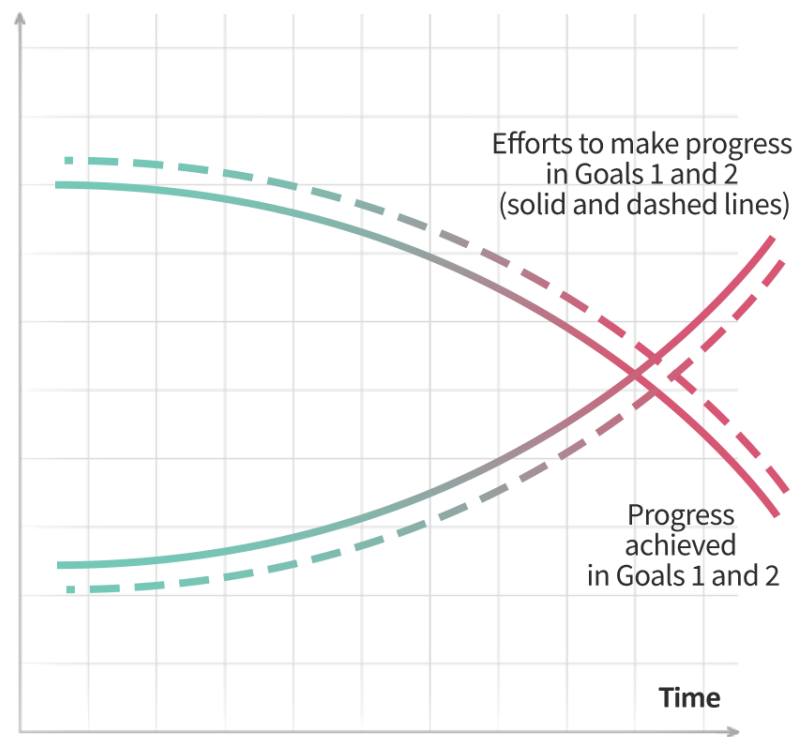

(b)

Figure 8. (a) The causal configuration and (b) a potential dynamic behaviour in Tragedy of the Commons. The major feedback interactions in (a) and their corresponding impacts in (b) are colour coded.

\section{INTERACTION ARCHETYPES AS A PRACTICAL TOOL}

Recent studies have suggested that decision-makers are less concerned about accuracy, precision, or the quantitative nature of SDG knowledge, and instead prioritise simplicity, flexibility, and ease of understanding of the results (61). Our proposed interaction archetypes specifically address this need and provide a simple and practical tool for researchers and practitioners to understand and analyse SDG synergies and trade-offs as already shown in previous examples (Table 2). As diagnostic tools, interaction archetype analysis can inform deeper causal mechanisms of SDG progress or policy resistance and show their potential dynamic behaviour patterns $(60,62)$. Through links to underlying causal mechanisms and dynamic behaviour, these archetypes can also be used as prospective tools for identifying potential future unintended consequences of both short-term and transformational solutions and for designing sustainable development strategies which can minimise trade-offs and capitalise upon synergies (42). Strategies identified through the lens of these archetypes can be also evaluated with computational simulation approaches and scenario analysis. 
Table 2. The practical use of different archetypes for analysing interactions in sustainability science. Rows in the first column with asterisk indicate studies that did not explicitly refer to the term 'SDG', but their contents were still related to one or more goals. See Supplementary Materials for the review process.

\begin{tabular}{|c|c|c|c|c|c|}
\hline Interaction(s) & Related archetype(s) & Practical use & Analysis & Place/scale/sector & Citation \\
\hline $\begin{array}{l}\text { SDGs } 2-16^{*} \\
\text { synergy, SDGs 2- } \\
15^{*} \text { synergy }\end{array}$ & $\begin{array}{l}\text { Tragedy of the Commons, } \\
\text { Band-Aid Solutions, Success } \\
\text { to the Successful }\end{array}$ & $\begin{array}{l}\text { To characterise recurring } \\
\text { problems of village pasture } \\
\text { management }\end{array}$ & $\begin{array}{l}\text { Quantitative } \\
\text { and } \\
\text { qualitative }\end{array}$ & $\begin{array}{l}\text { Azerbaijan and } \\
\text { Georgia (Caucasus); } \\
\text { regional and local; } \\
\text { agriculture sector }\end{array}$ & $\begin{array}{l}\text { Neudert et } \\
\text { al. }(59)\end{array}$ \\
\hline $\begin{array}{l}\text { SDGs 6-7-2-15*, } \\
\text { Both synergy and } \\
\text { trade-off }\end{array}$ & $\begin{array}{l}\text { Limits to Progress, Success } \\
\text { to the Successful }\end{array}$ & $\begin{array}{l}\text { To understand and analyse } \\
\text { the dynamic interactions } \\
\text { between living and non- } \\
\text { living elements in a reservoir } \\
\text { system }\end{array}$ & Qualitative & $\begin{array}{l}\text { West Java } \\
\text { (Indonesia); regional } \\
\text { (catchment scale); } \\
\text { water-energy-food- } \\
\text { land nexus }\end{array}$ & Bahri (37) \\
\hline $\begin{array}{l}\text { SDG 16* (also } \\
\text { implicitly SDGs } \\
2-7-13-15)\end{array}$ & $\begin{array}{l}\text { Fixes That Fail, Limits to } \\
\text { Progress, other archetypes }\end{array}$ & $\begin{array}{l}\text { To explain causal links } \\
\text { between governance } \\
\text { structures that influence the } \\
\text { policy process pathway over } \\
\text { time in the bioenergy sector }\end{array}$ & Qualitative & $\begin{array}{l}\text { Emilia Romagna } \\
\text { (Italy) and Hedmark } \\
\text { (Norway); regional } \\
\text { and sectoral; } \\
\text { bioenergy sector }\end{array}$ & $\begin{array}{l}\text { Cavicchi } \\
(32)\end{array}$ \\
\hline $\begin{array}{l}\text { SDGs } 1-2 * \\
\text { synergy }\end{array}$ & $\begin{array}{l}\text { Band-Aid Solutions, } \\
\text { Escalating Tensions, Fixes } \\
\text { That Fail, Limits to Progress, } \\
\text { Success to the Successful, } \\
\text { Tragedy of the Commons }\end{array}$ & $\begin{array}{l}\text { To understand the economic } \\
\text { behaviour and root causes of } \\
\text { problems in the piggery } \\
\text { industry. }\end{array}$ & Qualitative & $\begin{array}{l}\text { Ghana; national; } \\
\text { agriculture sector. }\end{array}$ & $\begin{array}{l}\text { Banson et } \\
\text { al. }(36)\end{array}$ \\
\hline $\begin{array}{l}\text { SDGs } 2-8 * \text { trade- } \\
\text { off }\end{array}$ & $\begin{array}{l}\text { Limits to Progress, Band-Aid } \\
\text { Solutions, Eroding Ambitions }\end{array}$ & $\begin{array}{l}\text { To analyse and anticipate } \\
\text { challenges in the } \\
\text { development of organic } \\
\text { farming in the EU }\end{array}$ & Qualitative & $\begin{array}{l}\text { European Union; } \\
\text { regional; organic } \\
\text { farming }\end{array}$ & $\begin{array}{l}\text { Brzezina et } \\
\text { al. }(34)\end{array}$ \\
\hline $\begin{array}{l}\text { SDGs } 2-15^{*} \\
\text { trade-off }\end{array}$ & $\begin{array}{l}\text { Fixes That Fail, Success to } \\
\text { the Successful, Eroding } \\
\text { Ambitions }\end{array}$ & $\begin{array}{l}\text { To understand impacts on } \\
\text { soil resources and rural } \\
\text { communities from land use } \\
\text { change, particularly } \\
\text { unintended consequences }\end{array}$ & Quantitative & $\begin{array}{l}\text { North-central USA; } \\
\text { regional; land sector }\end{array}$ & $\begin{array}{l}\text { Turner et } \\
\text { al. }(42)\end{array}$ \\
\hline $\begin{array}{l}\text { SDGs 6-2-15* } \\
\text { trade-off }\end{array}$ & $\begin{array}{l}\text { Band-Aid Solutions, Tragedy } \\
\text { of the Commons, }\end{array}$ & $\begin{array}{l}\text { To help setting boundaries } \\
\text { for case study analysis }\end{array}$ & Qualitative & $\begin{array}{l}\text { Lake Urmia basin } \\
\text { (Iran), Zayendah- } \\
\text { Rood basin (Iran); } \\
\text { regional, water sector }\end{array}$ & $\begin{array}{l}\text { Nabavi et } \\
\text { al. (63) }\end{array}$ \\
\hline $\begin{array}{l}\text { SDGs } 2-6^{*} \\
\text { synergy }\end{array}$ & $\begin{array}{l}\text { New patterns from } \\
\text { combining Limits to } \\
\text { Progress, Tragedy of the } \\
\text { Commons }\end{array}$ & $\begin{array}{l}\text { To analyse behaviour of } \\
\text { people, process and policy of } \\
\text { food waste and food security }\end{array}$ & Qualitative & $\begin{array}{l}\text { Conceptual analysis } \\
\text { in food sector }\end{array}$ & $\begin{array}{l}\text { Sharif and } \\
\text { Irani }(38)\end{array}$ \\
\hline $\begin{array}{l}\text { SDG } 6 \text { synergy } \\
\text { and trade-off with } \\
\text { all SDGs }\end{array}$ & $\begin{array}{l}\text { Limits to Progress, } \\
\text { Downplayed Problems }\end{array}$ & $\begin{array}{l}\text { To map the interlinkages } \\
\text { between the SDGs and } \\
\text { identify the leverage points }\end{array}$ & Qualitative & $\begin{array}{l}\text { Conceptual analysis } \\
\text { in all SDGs }\end{array}$ & $\begin{array}{l}\text { Zhang et al. } \\
\text { (35) }\end{array}$ \\
\hline $\begin{array}{l}\text { SDGs } 2-15^{*} \\
\text { trade-off }\end{array}$ & $\begin{array}{l}\text { Band-Aid Solutions, Limits } \\
\text { to Progress, Success to the } \\
\text { Successful, Tragedy of the } \\
\text { Commons, other archetypes }\end{array}$ & $\begin{array}{l}\text { To gain insight into patterns } \\
\text { of behaviour in the } \\
\text { agriculture sector in response } \\
\text { to current policies }\end{array}$ & Qualitative & $\begin{array}{l}\text { Ghana; national; } \\
\text { agriculture sector }\end{array}$ & $\begin{array}{l}\text { Banson et } \\
\text { al. (53) }\end{array}$ \\
\hline
\end{tabular}


To be able to use archetypes as thinking tools, we need to have case-specific evidence to infer causality that govern interactions in practice. One way to obtain and analyse evidence in practice for archetypes is through event history analysis (64), which helps conceptualise causality of interactions by studying different sequences of events and their causation, critical incidents, and side-effects in a systematic manner. While event history analysis requires data to infer causality, it is proven to be more useful and systematic in analysing complex longitudinal data and deriving meaningful narratives from them. The use of storylines or narratives captures the richness of information about the underlying interaction mechanisms in a case study, which can be overlooked when using other (e.g., statistical) data collection and analysis methods. These qualities make event history analysis a more fit-for-purpose process for qualitative analyses as evidenced by its successful use in other areas such as mapping patterns of change in technological innovation and socio-technical transitions (65-67). We can learn from these applications and use similar processes to distil evidence and identify SDG interaction archetypes in case studies.

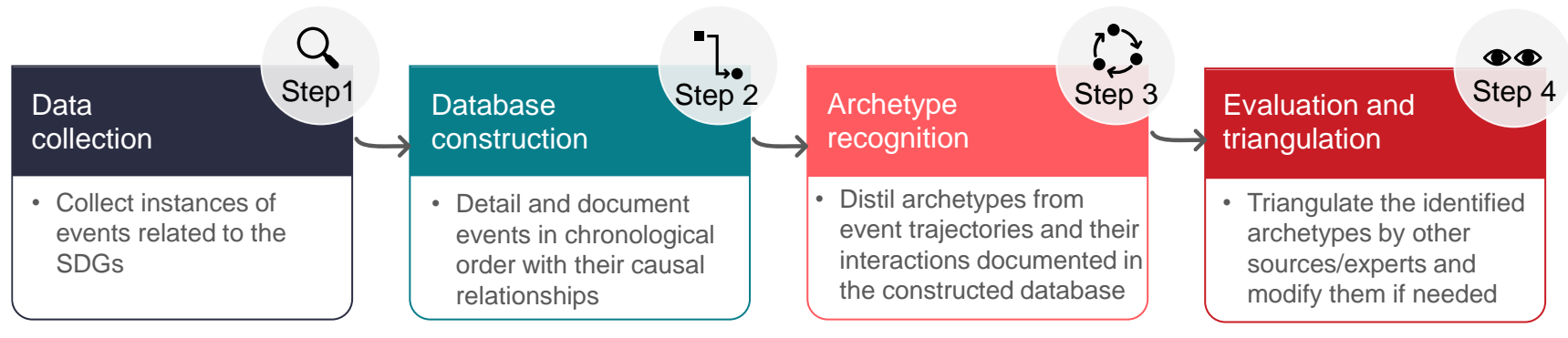

Figure 9. Steps to take to operationalise the interaction archetype approaches in practice

Operationalising interaction archetypes with event history analysis can start by data collection (Figure 9). The basic unit of analysis for data collection is the event. An event can be defined as an instance of (e.g., actors, institutions, resource) change with respect to an SDG which carries public importance and contributes to overall sustainability. The examples of such events can include the construction of a new energy plant, the implementation of a carbon price policy, or the emergence of a new sustainability issue. Events can be identified from a variety of sources, including scientific articles, newspapers, periodicals, reports, websites, and expert knowledge.

Once case study data is collected, the second step is database construction detailing events in chronological order with their causal relationships and connections to different SDGs specified. This can be done by assessing the collected data and identifying and categorising the reported events based on their (positive or negative) contributions to various SDGs and the type of interaction (e.g., synergy or trade-off) involved. An event may contribute to multiple SDGs and influence several synergies/trade-offs.

The third step is archetype recognition. This starts by the expert development of causal loop diagrams based on their domain knowledge. The expert analysis of interactions is an inductive exercise during which the proposed set of eight archetypes (or a combination of multiple archetypes to explain more complex interactions) is used to draw causal loop diagrams based on expert initial assumptions. An analysis of documented events can then support expert assumptions. This includes the analysis of event trajectories to characterise trends from collected data, indicating the fulfilment of different SDGs over a period of time and event interactions to characterise the causal chains of events based on their sequence, offering possible explanations for these outcomes. Both event trajectory and interaction analysis can be done qualitatively (e.g., checking explainability of causal chains with reference to documented events) or quantitatively (e.g., extracting casual chains from events with causal inference 
methods). The understanding of trends and interactions together can lead to a meaningful narrative, supporting expert assumptions about the causal loop diagrams and the identification of interaction archetype(s).

The final step is evaluation and triangulation. The construction of narratives and specification of related interaction archetypes that fit those narratives are subjective processes requiring substantial interpretation. To minimise potential biases in this process and avoid overfitting data to the archetypes, findings need to be evaluated and triangulated by including other expert opinions and/or further information about the case study. Interaction archetypes may need to be reconstructed with new data based on different interpretations of events and judgements about their causal relationship by different researchers.

\section{DISCUSSION}

\section{Opportunities}

\section{Synthesising knowledge across cases}

Interaction archetype analysis can play an important role in linking empirical data to interaction patterns and to causal statements. The presented typology of interactions can serve as a framework for knowledge synthesis from a large number of empirical findings compiled through different methods and from numerous case study applications (68). Knowledge synthesis will be independent of narrowly focused case studies and sustainability contexts, and generalised at an intermediate level of abstraction (31). It is therefore capable of inferring broader patterns of causal effects and configurations among various sustainability goals that are more generally applicable and understandable. Such a synthesis of knowledge across SDG studies is significant for understanding and acting on various socioeconomic and environmental challenges that operate beyond specific sectors and contexts. Knowledge synthesis can also play an important role in systematic theory development, where assuming a theory or hypothesis for observed sustainability interactions can be tested and/or explained by similar interactions in other cases/contexts.

\section{Transferring lessons across locations}

Many sustainability problems in different geographical locations are very similar in nature, and there are lessons to be learned from how different contexts/locations respond to the same problem, if the knowledge can be transferred through a common framework (see examples in water (69), agriculture (70), biodiversity (71), land-use (72)). Classifying typical SDG-related problems and intervention leverages into recurring archetypal patterns based on systems theory can help policy-makers and SDG planners by providing a comparative tool (73). This can foster learning about sustainability interactions and the experience of others in different locations and enhance knowledge transfer between areas which share the same causal mechanisms in a more coordinated way $(59,74,75)$.

\section{Structuring knowledge for modelling}

The understanding of interaction archetypes and linking causal effects to their underlying configurations can provide valuable information and inform model-based sustainability analyses (27). They provide a dynamic hypothesis that can help capture the co-evolving nature of socioeconomic and environmental processes, which could be simplified in the model structure. They can also inform modelling through revealing policy leverage points, side-effects, and contingencies as effective mechanisms to be included in models. Models, in turn, can also test and evaluate the qualitative understanding of interactions by reproducing feedback loops, non-linearity, and time delays described in archetypes - that is, features which are impractical to quantify with the typology of interactions alone. As with other disciplines (e.g., complexity science, resilience science, socio-ecological systems 
science, water research, social science), sustainability researchers interested in the SDGs will find these systems tools useful as they realise insights for SDG complexity which are not currently obtainable from established methods (e.g., statistical analysis (4), integrated assessment modelling (22)). This promotes innovative research designs in future SDG interaction studies, thereby contributing to the methodological advancement in sustainability research and practice.

\section{Challenges}

\section{Biases in understanding interactions and overfitting data to the archetypes}

The analysis of data in a case study can be influenced deliberately (e.g., personal preferences, beliefs, values) or unintentionally (e.g., unconscious mental framework, heuristics, presumptions). There is an extensive theoretical body of literature that has focused on these issues $(76,77)$. This can lead to potential biases, misjudgement, and data overfitting to reach some archetypal patterns with specific causal configurations. For example, stakeholder strategic motives or self-interest can lead to the deliberate ignorance of side-effects of short-sighted actions (e.g., Band-Aid Solutions) and instead blaming the slow progess on natural limiting conditions in the system (e.g., Limits to Progress). A similar problem to biases is to overfit or shoehorn the case study interactions into one of the eight archetypes. Archetypes are a good way to understand many SDG interactions, but not every interaction is directly explained by the eight presented here. The risks of such biases and data overfitting include framing relevant archetypes in a distorted representation of SDG interactions and misleading causal configurations; leading to sub-optimal polices if they are used in decision-making. Testing and supporting the recognition of archetypal patterns in case studies with more empirical data is one way of mitigating the risk of biases. Using a combination of connected archetypes to explain SDG interactions is another way of addressing biases and data overfitting. By mixing two or more of the current eight types of interactions together, a very large number of new (compound) interactions can emerge which can be used to explain more complex processes. Engagement with stakeholders can provide an opportunity to more closely assess the relevance and objectivity of the interactions in a case study and to co-develop them with relevant societal actors with potentially contrasting views of interactions and their causal processes (31). Modelling can also provide a systematic way of testing and evaluating the archetypes of a case study as hypotheses in a way that is less biased and less dependent upon individual judgements.

\section{Interactions across scales}

Progress towards the SDGs is shaped by a variety of socioeconomic and environmental processes that span multiple local (e.g., community, city), national, regional (e.g., political and economic union), and global scales, and issues that exist at one scale may manifest differently at another scale (78, 79). However, the use of the proposed interaction archetypes (and compound interactions resulting from their combination) for sustainability has remained primarily focused on higher (often national, regional, or global) scales, missing potential interactions across scales. More locally-focused approaches to the SDGs are required to better represent and account for bottom-up causal processes, and their up-scaling is the major contributor to processes at higher (e.g., global) scales (e.g., $(15,80,81))$. Multi-scale approaches are required to create nested patterns of interactions (e.g., regional supported by country-level sub-patterns (82)) and incorporate multiple levels of abstraction, each corresponding to scale-specific interactions (31).

\section{Uncertainty in interaction configurations}

Socio-environmental conditions and decision-making are inherently associated with uncertainties that could determine how interactions among the SDGs ultimately unfold and their concomitant sustainability outcomes. Such uncertainties can result from incomplete knowledge about the 
environment and future events (e.g., technological innovations, political shift, and ecological tipping points) as well as the diversity of stakeholder perspectives (e.g., epistemological, cultural, policy choices) and therefore lead to ambiguity in framing interactions (83). Uncertainty has so far had limited attention in analysing SDG synergies and trade-offs, and when uncertainty was considered it was mostly parametric uncertainty in model-based projections $(21,22)$. However, there are more pervasive forms of uncertainty, for example uncertainty in underlying causal configurations of interactions (e.g., relationships between variables, their feedback interactions) which cause unexpected dynamics and surprises in system behaviour and unfolding interactions. This structural form of uncertainty is seldom discussed and needs to be further investigated in relation to the structure of causal configurations in SDG interaction.

Integration with other methods from other areas such as exploratory modelling $(84,85)$ is one way for a systematic generation and impact assessment of alternative causal configurations and comparing their resulting SDG interactions. In an exploratory approach, the assessment and comparison of alternative causal configurations should not aim for agreement but rather focus on differences in the underpinning causal relationships. This can lead to new insights that would not have been possible without considering a diversity of causal configurations.

Another related challenge is the insufficient assessment of human and governance uncertainties in SDG interactions. Uncertainty analysis in the SDGs is often related to measurable socio-economic aspects (e.g., population growth, GDP) or biogeophysical factors (e.g., climate uncertainty, land productivity, water-use efficiency), thus leading to an underestimation of uncertainties related to human, behavioural, and governance processes (e.g., lifestyle behavioural change, policy instability). The incorporation of a social science perspective (e.g., incorporating behavioural aspects in the analysis of diet (86) and climate change mitigation (87)) can acknowledge largely overlooked forms of uncertainty and provide new insights about effective interventions and SDG progress (e.g., social tipping points (88)).

\section{CONCLUSION}

The SDGs are intertwined with coupled human-natural systems and are filled with synergies and trade-offs, but this complexity is often not sufficiently addressed in SDG analysis. To effectively pursue sustainable development, we need to draw upon interacting social, economic, and natural priorities in concert and adopt much more systems-oriented approaches to problem solving (89). We conceptualised different types of SDG interactions using system archetypes and present a practical tool that focuses on understanding synergies and trade-offs and how they can influence the behaviour and dynamics of a system. We used simple, multidisciplinary examples to illustrate how the proposed interaction types can be used to understand, explain, and obtain policy insights about some of most important sustainability synergies and trade-offs. We also discussed how our proposed archetypes can be operationalised and applied to future case studies for better understanding and progressing towards the SDGs. We discussed several opportunities arising from a systemic analysis of SDG interactions through archetypes, including synthesising knowledge across cases, transferring lessons from one case to another, and formalising knowledge for future modelling work. Despite many potential opportunities, we also mentioned some of the challenges in using them, such as the issue with biases in archetype mapping, the complexity of multi-scale interactions, and the challenge of representing uncertainty. Archetypal patterns derived from interactions are useful for better understanding the SDGs and explaining their behaviour. They can be also the first step towards more integrated policies and governance solutions that can specifically address systemic barriers in SDG interactions. 


\section{METHODS}

\section{Adopting systems tools}

We used two tools from systems thinking (90), i.e. systems archetypes and causal loop diagrams, as a means to frame and conceptualise SDG interactions. These tools have proved useful in broader sustainability research (e.g., for classifying climate vulnerabilities (91), land-use decision-making (92), governance barriers $(93)$, sectoral interactions $(53,94)$ ) but have not been used for framing SDG interactions.

Archetypes are often used for identifying generic patterns of behaviour and explaining causal mechanisms common to multiple socio-ecological and socio-technical systems (95-97). They help shift the analytical focus from simple behavioural correlations or a limited understanding of interactions between certain goals, to a generalised knowledge of recurring patterns, causes, and consequences across case studies (98). We analysed and interpreted SDG interactions through the lens of eight archetypes, which have been mentioned and frequently used in systems thinking (95, 99, 100): Fixes that Fail, Band-Aid Solutions (aka Shifting the Burden or Addiction), Eroding Ambitions (aka Eroding or Drifting Goals), Downplayed Problems (aka Growth and Underinvestment), Escalating Tensions (aka Escalation), Success to the Successful, Limits to Progress (aka Limits to Success or Growth), and Tragedy of the Commons. In conceptualising SDG interactions with systems archetypes, we sometimes modified their original names from systems science to better represent them and suit their new purpose in the SDG context. This is not unconventional given that different sources have already used different names for these archetypes depending on their application context.

The choice of these archetypes as our lens is justified by and meets the quality criteria mentioned for this class of qualitative analysis in the literature (101). First, the design of the selected archetypes is theoretically rigorous as it is rooted in systems thinking and has been extensively applied in systems modelling. Originally introduced by Senge (95) in the seminal work, The Fifth Discipline, the archetypes have been further popularised through a range of studies $(30,96,99,100)$. Second, the universality and comprehensiveness of these archetypes to represent the diversity of alternative interactions in complex general systems have been successfully tested in several empirical contexts (e.g., biodiversity (100), water (60), agriculture (59)). These eight archetypes can also be combined to create a much wider diversity of (compound) interactions representing more complex interactions.

Archetypes in a system are usually depicted using causal loop diagrams (102). Causal loop diagrams represent the structural configuration and feedback relationships among various system elements (SDGs in the context of this paper) which shape their dynamic behaviour over time. Different SDG elements are connected via causal links, shown by arrows, which represent (hypothesised) causal relationships rather than statistical correlations. The causal links are assigned positive or negative polarity to indicate synergies or trade-offs between two system elements, respectively. Polarity indicates the nature of relationship (i.e., what would happen if there were a change) rather than describing what their behaviour currently is. A positive relationship implies that a change in the cause variable changes the effect variable in the same direction. A negative relationship implies that a change in the cause variable results in a change in the effect variable in the opposite direction. A closed chain of causal relationships creates a feedback loop. Feedback loops which influence dynamic behaviour are marked with positive or negative identifiers indicating either a reinforcing (e.g., positive change in one system element leads to a positive change in another one, potentially with exponential behaviour) or balancing (e.g., a negative change in one system element leads to a negative change in another one) relationship over time, respectively. 


\section{Framing interactions}

We conceptualised different types of SDG interactions through the lens of systems archetypes and with the help of causal loop diagrams (see Table S1 for the description of each SDG). We showed, via the use of causal loop diagrams, how some of the most important SDG interactions (both synergies and trade-offs) identified in the literature can be characterised as one of a few archetypes. We used real-world examples of specific sustainability challenges resulting from one or a combination of the most common SDG synergies and trade-offs that were identified by Kroll et al. (3) to explain interactions from the perspective of each archetype in terms of the following characteristics:

- How are they created? Different interaction archetypes can represent different levels of complexity resulting from a range of effects of policy interventions including long-term sideeffects, time-delayed responses, and path dependency. We articulated how each archetype, with seemingly simple interactions, can add to SDG complexity. As each interaction archetype can be also motivated by different underlying causal structures, we explained the chain of causes and consequences in feedback loops to show underlying configurations. We used causal loop diagrams to explain how progress in one goal could be promoted or hindered by progress in another goal, and how one or a combination of causally related goals could produce a specific interaction archetype, with reference to empirical examples.

- What is their potential dynamic behaviour? Each interaction archetype can lead to insights about how the performance of the SDGs can evolve differently over time with lagging, accelerating, or tipping point behaviours. We explained a potential dynamic, time-dependent behaviour resulting from SDG interactions associated with each archetype.

- What are their policy implications? Each interaction archetype, with its specific causal configuration and dynamic behaviour, can provide different implications for SDG policy and planning (e.g., how to respond, where to intervene).

\section{Acknowledgements}

We would like to greatly thank Arash Shirmohammadi (IdeMedia Co) for graphic design in Figures 1 to 8.

\section{REFERENCES}

1. UN, "Transforming our world: the 2030 Agenda for Sustainable Development," Resolution adopted by the General Assembly on 25 September 2015 (The United Nations (UN), 2015).

2. M. Nilsson, D. Griggs, M. Visbeck, Policy: map the interactions between Sustainable Development Goals. Nature 534, 320-322 (2016).

3. C. Kroll, A. Warchold, P. Pradhan, Sustainable Development Goals (SDGs): Are we successful in turning trade-offs into synergies? Palgrave Commun. 5, 140 (2019).

4. P. Pradhan, L. Costa, D. Rybski, W. Lucht, J. P. Kropp, A Systematic Study of Sustainable Development Goal (SDG) Interactions. Earth's Future 5, 1169-1179 (2017).

5. S. Fuss, W. F. Lamb, M. W. Callaghan, J. Hilaire, F. Creutzig, T. Amann, T. Beringer, W. de Oliveira Garcia, J. Hartmann, T. Khanna, G. Luderer, G. F. Nemet, J. Rogelj, P. Smith, J. L. V. Vicente, J. Wilcox, M. del Mar Zamora Dominguez, J. C. Minx, Negative emissions-Part 2: Costs, potentials and side effects. Environmental Research Letters 13, 063002 (2018).

40 6. E. Meijers, D. Stead, Policy integration: what does it mean and how can it be achieved? A multidisciplinary review. paper presented at the Berlin Conference on the Human Dimensions of Global Environmental Change: Greening of Policies-Interlinkages and Policy Integration., Berlin, 2004. 
7. M. C. Lo Bue, S. Klasen, Identifying Synergies and Complementarities Between MDGs: Results from Cluster Analysis. Social Indicators Research 113, 647-670 (2013).

8. J. D. Sachs, From Millennium Development Goals to Sustainable Development Goals. The Lancet 379, 2206-2211 (2012).

59 9. P. Smith, J. E. Olesen, Synergies between the mitigation of, and adaptation to, climate change in agriculture. The Journal of Agricultural Science 148, 543-552 (2010).

10. S. Mathy, O. Blanchard, Proposal for a poverty-adaptation-mitigation window within the Green Climate Fund. Climate Policy 16, $752-767$ (2016).

11. D. P. van Vuuren, L. Batlle Bayer, C. Chuwah, L. Ganzeveld, W. Hazeleger, B. van den Hurk, T. van Noije, B. O'Neill, B. J. Strengers, A comprehensive view on climate change: coupling of earth system and integrated assessment models. Environmental Research Letters 7, 024012 (2012).

12. J. Stiglitz, K. Sen Amartya, J. Fitoussi, The measurement of economic performance and social progress revisited: reflections and overview. (Sciences Po publications, Paris, 2009).

13. L. Ibisch Pierre, T. Hoffmann Monika, S. Kreft, G. Pe'er, V. Kati, L. Biber-Freudenberger, A. DellaSala Dominick, M. Vale Mariana, R. Hobson Peter, N. Selva, A global map of roadless areas and their conservation status. Science 354, 1423-1427 (2016).

14. M. Pedercini, S. Arquitt, D. Collste, H. Herren, Harvesting synergy from sustainable development goal interactions. PNAS 116, 23021 (2019).

15. R. Bandari, E. A. Moallemi, R. E. Lester, D. Downie, B. A. Bryan, Prioritising Sustainable Development Goals, characterising interactions, and identifying solutions for local sustainability. Environ. Sci. Policy 127, 325-336 (2021).

16. H. L. van Soest, D. P. van Vuuren, J. Hilaire, J. C. Minx, M. J. H. M. Harmsen, V. Krey, A. Popp, K. Riahi, G. Luderer, Analysing interactions among Sustainable Development Goals with Integrated Assessment Models. Global Transitions 1, 210-225 (2019).

17. D. L. McCollum, L. G. Echeverri, S. Busch, S. Pachauri, S. Parkinson, J. Rogelj, V. Krey, J. C. Minx, M. Nilsson, A.-S. Stevance, K. Riahi, Connecting the sustainable development goals by their energy interlinkages. Environmental Research Letters 13, 033006 (2018).

18. C. C. Anderson, M. Denich, A. Warchold, J. P. Kropp, P. Pradhan, A systems model of SDG target influence on the 2030 Agenda for Sustainable Development. Sustainability Science, (2021).

19. D. Le Blanc, Towards Integration at Last? The Sustainable Development Goals as a Network of Targets. Sustainable Development 23, 176-187 (2015).

20. M. Obersteiner, B. Walsh, S. Frank, P. Havlík, M. Cantele, J. Liu, A. Palazzo, M. Herrero, Y. Lu, A. Mosnier, H. Valin, K. Riahi, F. Kraxner, S. Fritz, D. van Vuuren, Assessing the land resource-food price nexus of the Sustainable Development Goals. Sci. Adv. 2, e1501499 (2016).

21. L. Gao, B. A. Bryan, Finding pathways to national-scale land-sector sustainability. Nature 544, 217 (2017).

22. B. Soergel, E. Kriegler, I. Weindl, S. Rauner, A. Dirnaichner, C. Ruhe, M. Hofmann, N. Bauer, C. Bertram, B. L. Bodirsky, M. Leimbach, J. Leininger, A. Levesque, G. Luderer, M. Pehl, C. Wingens, L. Baumstark, F. Beier, J. P. Dietrich, F. Humpenöder, P. von Jeetze, D. Klein, J. Koch, R. Pietzcker, J. Strefler, H. Lotze-Campen, A. Popp, A sustainable development pathway for climate action within the UN 2030 Agenda. Nat. Clim. Change. 11, 656-664 (2021).

23. F. Fuso Nerini, J. Tomei, L. S. To, I. Bisaga, P. Parikh, M. Black, A. Borrion, C. Spataru, V. Castán Broto, G. Anandarajah, B. Milligan, Y. Mulugetta, Mapping synergies and trade-offs between energy and the Sustainable Development Goals. Nature Energy 3, 10-15 (2018). 
24. H. Schmidt, L. O. Gostin, E. J. Emanuel, Public health, universal health coverage, and Sustainable Development Goals: can they coexist? The Lancet 386, 928-930 (2015).

25. M. Herrero, P. K. Thornton, D. Mason-D'Croz, J. Palmer, B. L. Bodirsky, P. Pradhan, C. B. Barrett, T. G. Benton, A. Hall, I. Pikaar, J. R. Bogard, G. D. Bonnett, B. A. Bryan, B. M. Campbell, S. Christensen, M. Clark, J. Fanzo, C. M. Godde, A. Jarvis, A. M. Loboguerrero, A. Mathys, C. L. McIntyre, R. L. Naylor, R. Nelson, M. Obersteiner, A. Parodi, A. Popp, K. Ricketts, P. Smith, H. Valin, S. J. Vermeulen, J. Vervoort, M. van Wijk, H. H. E. van Zanten, P. C. West, S. A. Wood, J. Rockström, Articulating the effect of food systems innovation on the Sustainable Development Goals. The Lancet Planetary Health 5, e50-e62 (2021).

$1026 . \quad$ C. Allen, G. Metternicht, T. Wiedmann, M. Pedercini, Greater gains for Australia by tackling all SDGs but the last steps will be the most challenging. Nat. Sustain. 2, 1041-1050 (2019).

27. E. A. Moallemi, E. Bertone, S. Eker, L. Gao, K. Szetey, N. Taylor, B. A. Bryan, A review of systems modelling for local sustainability. Environmental Research Letters 16, 113004 (2021).

28. J. D. Sterman, System Dynamics Modeling: Tools for Learning in a Complex World. Calif. Manage. Rev. 43, 8-25 (2001).

29. G. Papachristos, A. Sofianos, E. Adamides, System interactions in socio-technical transitions: Extending the multi-level perspective. Environmental Innovation and Societal Transitions 7, 53-69 (2013).

30. P. M. Senge, J. D. Sterman, Systems thinking and organizational learning: Acting locally and thinking globally in the organization of the future. European Journal of Operational Research 59, 137-150 (1992).

31. D. Sietz, U. Frey, M. Roggero, Y. Gong, N. Magliocca, R. Tan, P. Janssen, T. Václavík, Archetype analysis in sustainability research methodological portfolio and analytical frontiers. Ecol. Soc. 24, (2019).

32. B. Cavicchi, A "system dynamics perspective" of bioenergy governance and local, sustainable development. Systems Research and Behavioral Science 37, 315-332 (2020).

33. R. Neudert, A. Salzer, N. Allahverdiyeva, J. Etzold, V. Beckmann, Archetypes of common village pasture problems in the South Caucasus: insights from comparative case studies in Georgia and Azerbaijan. Ecol. Soc. 24, (2019).

34. N. Brzezina, K. Biely, A. Helfgott, B. Kopainsky, J. Vervoort, E. Mathijs, Development of Organic Farming in Europe at the Crossroads: Looking for the Way Forward through System Archetypes Lenses. Sustainability 9, (2017).

35. Q. Zhang, C. Prouty, J. B. Zimmerman, J. R. Mihelcic, More than Target 6.3: A Systems Approach to Rethinking Sustainable Development Goals in a Resource-Scarce World. Engineering 2, 481-489 (2016).

36. K. E. Banson, N. C. Nguyen, D. Sun, D. K. Asare, S. Sowah Kodia, I. Afful, J. Leigh, Strategic Management for Systems Archetypes in the Piggery Industry of Ghana-A Systems Thinking Perspective. Systems 6, (2018).

37. M. Bahri, Analysis of the water, energy, food and land nexus using the system archetypes: A case study in the Jatiluhur reservoir, West Java, Indonesia. Sci. Total Environ. 716, 137025 (2020).

38. A. M. Sharif, Z. Irani, People, process and policy perspectives on food security. Transforming Government: People, Process and Policy 10, 359-367 (2016).

39. S. Onyeiwu, E. Pallant, M. Hanlon, Sustainable and unsustainable agriculture in Ghana and Nigeria: 1960-2009. Ecosyst. Sustain. Dev 3, 211-222 (2011).

40. S. Carter, M. Herold, V. Avitabile, S. de Bruin, V. De Sy, L. Kooistra, M. C. Rufino, Agriculture-driven deforestation in the tropics from 1990-2015: emissions, trends and uncertainties. Environmental Research Letters 13, 014002 (2017). 
41. C. P. O. Reyer, S. Adams, T. Albrecht, F. Baarsch, A. Boit, N. Canales Trujillo, M. Cartsburg, D. Coumou, A. Eden, E. Fernandes, F. Langerwisch, R. Marcus, M. Mengel, D. Mira-Salama, M. Perette, P. Pereznieto, A. Rammig, J. Reinhardt, A. Robinson, M. Rocha, B. Sakschewski, M. Schaeffer, C.-F. Schleussner, O. Serdeczny, K. Thonicke, Climate change impacts in Latin America and the Caribbean and their implications for development. Regional Environmental Change 17, 1601-1621 (2017).

42. B. L. Turner, M. Wuellner, T. Nichols, R. Gates, L. O. Tedeschi, B. H. Dunn, A systems approach to forecast agricultural land transformation and soil environmental risk from economic, policy, and cultural scenarios in the north central United States (2012-2062). International Journal of Agricultural Sustainability 15, 102-123 (2017).

10 43. B. Soergel, E. Kriegler, B. L. Bodirsky, N. Bauer, M. Leimbach, A. Popp, Combining ambitious climate policies with efforts to eradicate poverty. Nat. Commun. 12, 2342 (2021).

44. M. S. Shiru, S. Shahid, A. Dewan, E.-S. Chung, N. Alias, K. Ahmed, Q. K. Hassan, Projection of meteorological droughts in Nigeria during growing seasons under climate change scenarios. Sci. Rep. 10, 10107 (2020).

45. I. Gençsü, M. McLynn, M. Runkel, M. Trilling, L. van der Burg, L. Worrall, S. Whitley, Z. Florian, "Phaseout 2020: monitoring Europe's fossil fuel subsidies," (Overseas Development Institute, London, 2017).

46. S. Acar, A. E. Yeldan, Environmental impacts of coal subsidies in Turkey: A general equilibrium analysis. Energy Policy 90, 1-15 (2016).

47. D. Nong, M. Siriwardana, Potential impacts of the Emissions Reduction Fund on the Australian economy. Energy Econ. 74, 387-398 (2018).

48. B. Greg, S. Andrew, S. Will, et al., Australia's rising greenhouse gas emissions. (2018).

49. H. X. Li, D. J. Edwards, M. R. Hosseini, G. P. Costin, A review on renewable energy transition in Australia: An updated depiction. Journal of Cleaner Production 242, 118475 (2020).

50. M. F. Ahmed, M. S. Islam, Urbanization and Environmental Problem: An Empirical Study In Sylhet City,Bangladesh. Research on Humanities and Social Sciences 4, 161-172 (2014).

51. K. Boadi, M. Kuitunen, K. Raheem, K. Hanninen, Urbanisation Without Development: Environmental and Health Implications in African Cities. Environ. Dev. Sustainability 7, 465-500 (2005).

52. M. Saberi, H. Wu, R. Amoh-Gyimah, J. Smith, D. Arunachalam, Measuring housing and transportation affordability: A case study of Melbourne, Australia. J. Transp. Geogr. 65, 134-146 (2017).

53. K. E. Banson, N. C. Nguyen, O. J. H. Bosch, Using System Archetypes to Identify Drivers and Barriers for Sustainable Agriculture in Africa: A Case Study in Ghana. Systems Research and Behavioral Science 33, 79-99 (2016).

54. R. Damania, J. Russ, D. Wheeler, A. F. Barra, The Road to Growth: Measuring the Tradeoffs between Economic Growth and Ecological Destruction. World Devel. 101, 351-376 (2018).

55. J. Parikh, K. Parikh, Growing Pains: Meeting India's Energy Needs in the Face of Limited Fossil Fuels. IEEE Power and Energy Magazine 10, 59-66 (2012).

56. E. A. Moallemi, F. J. de Haan, J. M. Webb, B. A. George, L. Aye, Transition dynamics in state-influenced niche empowerments: Experiences from India's electricity sector. Technological Forecasting \& Social Change 116, 129-141 (2017).

57. G. Rasul, Managing the food, water, and energy nexus for achieving the Sustainable Development Goals in South Asia. Environmental Development 18, 14-25 (2016).

58. D. Poblete, S. Vicuña, F. J. Meza, E. Bustos, in IWA World Congress on Water, Climate and Energy. (2012). 
59. R. Neudert, A. Salzer, N. Allahverdiyeva, J. Etzold, V. Beckmann, Archetypes of common village pasture problems in the South Caucasus insights from comparative case studies in Georgia and Azerbaijan. Ecol. Soc. 24, (2019).

60. F. Zare, A. Bagheri, S. Elsawah, Using system archetypes for problem framing and a qualitative analysis: a case study in Iranian water resource management. paper presented at the The 22nd International Congress on Modelling and Simulation (MODSIM), Hobart, Tasmania, Australia. 3-8 December, pp. 1433-1439., 2017.

61. L. Di Lucia, R. Slade, J. Khan, Decision-making fitness of methods to understand Sustainable Development Goal interactions. Nat. Sustain., (2021).

62. A. Mokhtar, S. Aram, Systemic insights into agricultural groundwater management: case of Firuzabad Plain, Iran. Water Policy 19, 867-885 (2017).

63. E. Nabavi, K. A. Daniell, H. Najafi, Boundary matters: the potential of system dynamics to support sustainability? Journal of Cleaner Production In Press, (2016).

64. M. S. Poole, Organizational change and Innovation processes : theory and methods for research. (New York ; Oxford : Oxford University Press, 2000., 2000).

65. M. P. Hekkert, S. O. Negro, Functions of innovation systems as a framework to understand sustainable technological change: Empirical evidence for earlier claims. Technol. Forecast. Soc. Change 76, 584594 (2009).

66. M. P. Hekkert, R. A. A. Suurs, S. O. Negro, S. Kuhlmann, R. E. H. M. Smits, Functions of innovation systems: A new approach for analysing technological change. Technol. Forecast. Soc. Change 74, 413432 (2007).

67. R. A. Suurs, Motors of Sustainable Innovation: Towards a Theory on the Dynamics of Technological Innovation Systems. Utrecht University, The Netherlands (2009).

68. N. R. Magliocca, E. C. Ellis, G. R. H. Allington, A. de Bremond, J. Dell'Angelo, O. Mertz, P. Messerli, P. Meyfroidt, R. Seppelt, P. H. Verburg, Closing global knowledge gaps: Producing generalized knowledge from case studies of social-ecological systems. Global Environ. Change 50, 1-14 (2018).

69. A. AghaKouchak, H. Norouzi, K. Madani, A. Mirchi, M. Azarderakhsh, A. Nazemi, N. Nasrollahi, A. Farahmand, A. Mehran, E. Hasanzadeh, Aral Sea syndrome desiccates Lake Urmia: Call for action. J. Great Lakes Res. 41, 307-311 (2015).

70. L. Cabral, A. Shankland, Narratives of Brazil-Africa cooperation for agricultural development: new paradigms? China Braz. Afr. Agric. (CBAA) Project Working Pap 51, 1-27 (2013).

71. A. Gonzalez, B. J. Cardinale, G. R. H. Allington, J. Byrnes, K. Arthur Endsley, D. G. Brown, D. U. Hooper, F. Isbell, M. I. O'Connor, M. Loreau, Estimating local biodiversity change: a critique of papers claiming no net loss of local diversity. Ecology 97, 1949-1960 (2016).

72. P. Meyfroidt, K. M. Carlson, M. E. Fagan, V. H. Gutiérrez-Vélez, M. N. Macedo, L. M. Curran, R. S. DeFries, G. A. Dyer, H. K. Gibbs, E. F. Lambin, D. C. Morton, V. Robiglio, Multiple pathways of commodity crop expansion in tropical forest landscapes. Environmental Research Letters 9, 074012 (2014).

73. M. Kok, M. Lüdeke, P. Lucas, T. Sterzel, C. Walther, P. Janssen, D. Sietz, I. de Soysa, A new method for analysing socio-ecological patterns of vulnerability. Regional Environmental Change 16, 229-243 (2016).

74. C. Oberlack, D. Sietz, E. Bürgi Bonanomi, A. de Bremond, J. Dell'Angelo, K. Eisenack, E. C. Ellis, G. Epstein, M. Giger, A. Heinimann, C. Kimmich, M. T. J. Kok, D. Manuel-Navarrete, P. Messerli, P. Meyfroidt, T. Václavík, S. Villamayor-Tomas, Archetype analysis in sustainability research: meanings, 
75. K. Eisenack, C. Oberlack, D. Sietz, Avenues of archetype analysis: roots, achievements, and next steps in sustainability research. Ecol. Soc. 26, (2021).

76. P. D. Glynn, A. A. Voinov, C. D. Shapiro, P. A. White, From data to decisions: Processing information, biases, and beliefs for improved management of natural resources and environments. Earth's Future 5, 356-378 (2017).

77. E. A. Moallemi, F. Zare, P. M. Reed, S. Elsawah, M. J. Ryan, B. A. Bryan, Structuring and evaluating decision support processes to enhance the robustness of complex human-natural systems. Environ. Model. Software 123, 1045-1051 (2020).

78. E. A. Moallemi, S. Malekpour, M. Hadjikakou, R. Raven, K. Szetey, D. Ningrum, A. Dhiaulhaq, B. A. Bryan, Achieving the Sustainable Development Goals requires transdisciplinary innovation at the local scale. One Earth 3, 300-313 (2020).

79. E. A. Moallemi, S. Malekpour, M. Hadjikakou, R. Raven, K. Szetey, M. M. Moghadam, R. Bandari, R. Lester, B. A. Bryan, Local Agenda 2030 for sustainable development. The Lancet Planetary Health $\mathbf{3}$, 240-241 (2019).

80. K. Szetey, E. A. Moallemi, E. Ashton, M. Butcher, B. Sprunt, B. A. Bryan, Co-creating local socioeconomic pathways for achieving the sustainable development goals. Sustainability Science, (2021).

81. K. Szetey, E. A. Moallemi, E. Ashton, M. Butcher, B. Sprunt, B. A. Bryan, Participatory planning for local sustainability guided by the Sustainable Development Goals. Ecol. Soc. 26, 16 (2021).

82. D. Sietz, J. C. Ordoñez, M. T. J. Kok, P. Janssen, H. B. M. Hilderink, P. Tittonell, H. Van Dijk, Nested archetypes of vulnerability in African drylands: where lies potential for sustainable agricultural intensification? Environmental Research Letters 12, 095006 (2017).

83. W. E. Walker, V. A. Marchau, J. H. Kwakkel, in Public Policy Analysis., W. A. H. Thissen, W. E. Walker, Eds. (Springer, Berlin, 2013), pp. 215-261.

84. E. A. Moallemi, J. Kwakkel, F. de Haan, B. A. Bryan, Exploratory modeling for analyzing coupled human-natural systems under uncertainty. Global Environ. Change 102186, 102186 (2020).

85. S. Bankes, Exploratory modeling for policy analysis. Oper. Res. 41, 435-449 (1993).

86. S. Eker, G. Reese, M. Obersteiner, Modelling the drivers of a widespread shift to sustainable diets. Nat. Sustain., (2019).

87. B. Beckage, L. J. Gross, K. Lacasse, E. Carr, S. S. Metcalf, J. M. Winter, P. D. Howe, N. Fefferman, T. Franck, A. Zia, A. Kinzig, F. M. Hoffman, Linking models of human behaviour and climate alters projected climate change. Nat. Clim. Change. 8, 79-84 (2018).

88. I. M. Otto, J. F. Donges, R. Cremades, A. Bhowmik, R. J. Hewitt, W. Lucht, J. Rockström, F. Allerberger, M. McCaffrey, S. S. P. Doe, A. Lenferna, N. Morán, D. P. van Vuuren, H. J. Schellnhuber, Social tipping dynamics for stabilizing Earth's climate by 2050. PNAS 117, 2354 (2020).

89. P. Matson, Systems-level partnerships for sustainability at scale. Nat. Sustain. 5, 1-2 (2022).

90. J. Sterman, Business dynamics: systems thinking and modeling for a complex world. (Irwin-McGrawHill, USA, 2000).

91. M. Vidal Merino, D. Sietz, F. Jost, U. Berger, Archetypes of Climate Vulnerability: a Mixed-method Approach Applied in the Peruvian Andes. Climate and Development 11, 418-434 (2019).

92. Ž. Malek, B. Douw, J. Van Vliet, E. H. Van Der Zanden, P. H. Verburg, Local land-use decision-making in a global context. Environmental Research Letters 14, 083006 (2019).

93. C. Oberlack, K. Eisenack, Archetypical barriers to adapting water governance in river basins to climate change. Journal of Institutional Economics 14, 527-555 (2018). 
94. M. Pejic Bach, J. Zoroja, M. Merkac-Skok, Social responsibility in tourism: system archetypes approach. Kybernetes 43, 587-600 (2014).

95. P. M. Senge, The Fifth Discipline: The Art and Practice of Learning Organization. (Doubleday, New York, 1990).

5 96. D. H. Meadows, Thinking in systems: A primer. D. Wright, Ed., (Chelsea Green Publishing, Vermont, USA, 2008).

97. D. H. Meadows, D. L. Meadows, J. Randers, W. W. Behrens, The limits to growth. New York 102, 27 (1972).

98. E. Wolstenholme, Using generic system archetypes to support thinking and modelling. System Dynamics Review: The Journal of the System Dynamics Society 20, 341-356 (2004).

99. D. Kim, Systems Archetypes. Toolbox Reprint Series. (Pegasus Communications, Waltham, MA, 1992).

100. L. M. Hallett, R. J. Hobbs, Thinking systemically about ecological interventions: what do system archetypes teach us? Restor. Ecol. 28, 1017-1025 (2020).

15 101. K. Eisenack, S. Villamayor-Tomas, G. Epstein, C. Kimmich, N. Magliocca, D. Manuel-Navarrete, C. Oberlack, M. Roggero, D. Sietz, Design and quality criteria for archetype analysis. Ecol. Soc. 24, (2019).

102. D. C. Lane, The emergence and use of diagramming in system dynamics: a critical account. Systems Research and Behavioral Science 25, 3-23 (2008). 